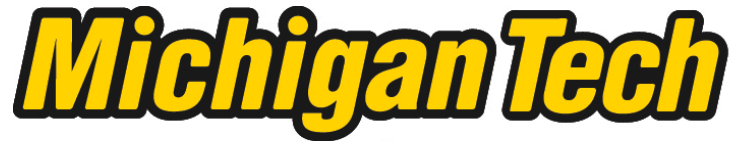 \\ Michigan Technological University Create the Future Digital Commons @ Michigan Tech
}

Dissertations, Master's Theses and Master's Reports - Open

Dissertations, Master's Theses and Master's

Reports

2012

\section{Expansion of mortar bars in the presence of potassium acetate deicer}

Gerald C. Anzalone III

Michigan Technological University

Follow this and additional works at: https://digitalcommons.mtu.edu/etds

Part of the Civil and Environmental Engineering Commons

Copyright 2012 Gerald C. Anzalone III

\section{Recommended Citation}

Anzalone, Gerald C. III, "Expansion of mortar bars in the presence of potassium acetate deicer ", Master's Thesis, Michigan Technological University, 2012.

https://doi.org/10.37099/mtu.dc.etds/216

Follow this and additional works at: https://digitalcommons.mtu.edu/etds

Part of the Civil and Environmental Engineering Commons 


\title{
EXPANSION OF MORTAR BARS IN THE PRESENCE OF POTASSIUM ACETATE DEICER
}

By

Gerald C. Anzalone III

\begin{abstract}
A THESIS
Submitted in partial fulfillment of the requirements for the degree of

MASTER OF SCIENCE

(Civil Engineering)
\end{abstract}

MICHIGAN TECHNOLOGICAL UNIVERSITY

2012

(C)2012 Gerald C. Anzalone III 
This thesis "Expansion of Mortar Bars in the Presence of Potassium Acetate Deicer," is hereby approved in partial fulfillment of the requirements for the Degree of MASTER OF SCIENCE IN CIVIL ENGINEERING.

Department of Civil and Environmental Engineering

Signatures:

\begin{tabular}{cc} 
Thesis Advisor & \\
\cline { 2 - 2 } Department Chair & \\
\cline { 2 - 2 } Dr. Lawrence L. Sutter \\
Date
\end{tabular}




\section{Contents}

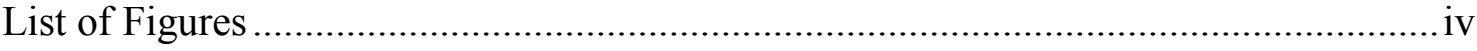

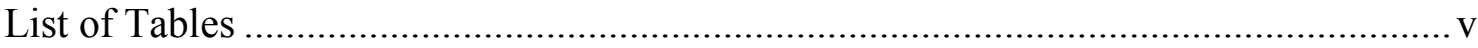

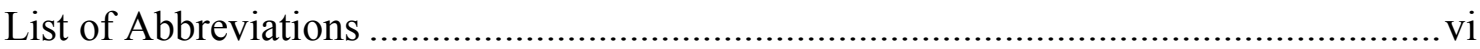

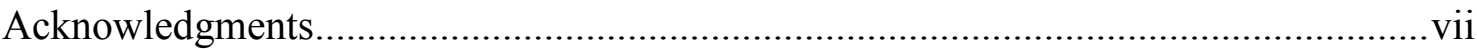

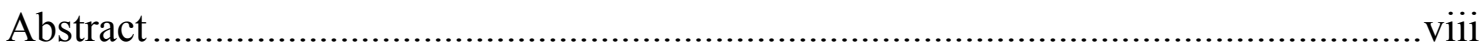

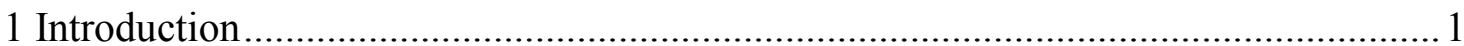

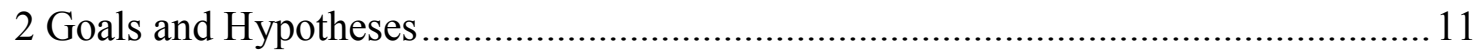

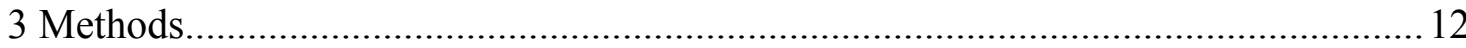

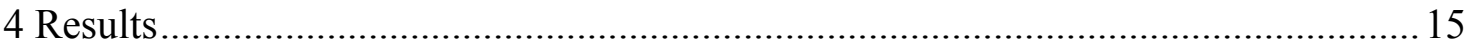

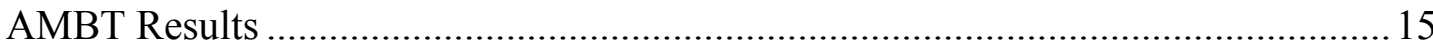

Petrographic examination of AMBT specimens......................................................25

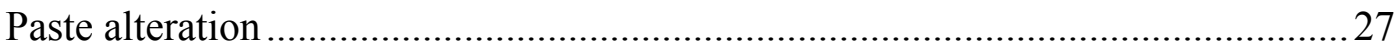

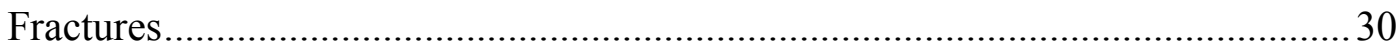

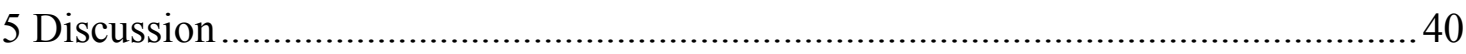

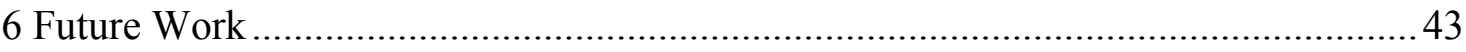

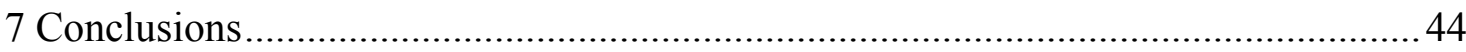

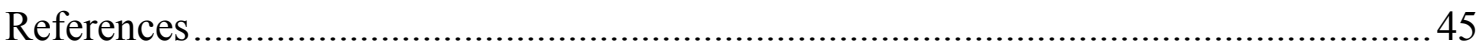




\section{List of Figures}

Figure 4.1: ASTM C1260 expansion curves for Ottawa sand and local basalt 16

Figure 4.2: ASTM C1260 expansion curves for Sioux quartzite 17

Figure 4.3: ASTM C1260 expansion grouped by soak solution................................... 18

Figure 4.4: C1567 expansion rate curves with Sioux quartzite 19

Figure 4.5: C1567 expansion rate curves with Sioux quartzite 20

Figure 4.6: C1567 expansion rate curves with Spratt limestone 21

Figure 4.7: C1567 expansion rate curves with Spratt limestone 22

Figure 4.8: C1567 expansion rate curves with Sioux quartzite 23

Figure 4.9: C1567 expansion rate curves with Spratt limestone 24

Figure 4.10: Images of thin sections of ASTM C1260 Ottawa sand 32

Figure 4.11: Images of thin sections of ASTM C1260 SRA 33

Figure 4.12: Images of thin sections of ASTM C1260 Spratt limestone 34

Figure 4.13: Images of thin sections of ASTM C1260 Sioux quartzite. 35

Figure 4.14: Micrographs of Ottawa sand grains in thin section 36

Figure 4.15: Micrographs of SRA grains in thin section 37

Figure 4.16: Micrographs of Spratt limestone grains in thin section............................ 38

Figure 4.17: Micrographs of Sioux quartzite grains in thin section 39 


\section{List of Tables}

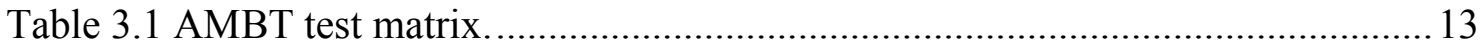

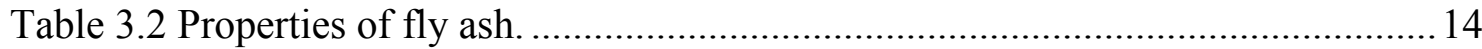




\section{List of Abbreviations}

AMBT - Accelerated Mortar Bar Testing

ASR - Alkali-Silica Reactivity

KAc - Potassium Acetate (deicer)

SCM - Supplementary Cementitious Material 


\section{Acknowledgments}

The research contemplated in this thesis would not be possible without the support of the Portland Cement Association whose generous contributions are duly noted and greatly appreciated.

Thanks also to Dr. Larry Sutter who provided mini crash courses covering material new and foreign and for supporting research ideas that strayed from the conventional.

Dr. Karl Peterson's tutelage and incredible patience in the lab helped transform ideas into concrete, tangible items capable of withstanding the rigors of materials characterization. Your long-distance support has been greatly appreciated as well!

Thanks to my kids who stood by the decision to relocate the family in order to pursue this late-in-life, selfish dream of returning to school.

Finally, thanks to my lovely wife for enduring the endless hours of chatter about subjects I fear boring and uninteresting to her. Thank you, too for proof reading and correcting! 


\begin{abstract}
Carboxylate-based deicing and anti-icing chemicals became widely used in the mid 1990s, replacing more environmentally burdensome chemicals. Within a few years of their adoption, distress of portland cement concrete runways was reported by a few airports using the new chemicals. Distress manifested characteristics identical to that of alkali silica reactivity (ASR), but onset occurred early in the pavement's operating life and with pavements thought to contain innocuous aggregate. The carboxylate-based deicing chemicals were suspected of exacerbating ASR-like expansion.

Innocuous, moderately, and highly reactive aggregates were tested using modified ASTM C1260 and ASTM C1567 procedures with soak solutions containing deicer solutions and sodium hydroxide or potassium hydroxide. ASR-like expansion is exacerbated in the presence of potassium acetate. The expansion rate produced by a given aggregate is also a function of the alkali hydroxide used. Petrographic analyses were performed on thin sections prepared from mortar bars used in the experiments. Expansion occurred via two mechanisms; rupture of aggregate grains and expansion of paste.
\end{abstract}




\section{Introduction}

Airports located where freezing precipitation events occur employ both mechanical and chemical methods for maintaining safe runways clear of snow and ice. Plows, brushes and shovels are not capable of removing all ice from the surface of runways and deicing or anti-icing chemicals are required. The effectiveness of these chemicals lies in their ability to decrease the temperature at which water freezes (freezing point depression).

Anti-icing is done in anticipation of a freezing event with deicing chemicals being applied directly to the surface of the runway prior to precipitation, reducing the adhesion of ice and making it easier to remove mechanically. Anti-icing agents are typically applied to the surface as aqueous solutions. Deicing is the process of applying deicing chemicals following deposition of ice or snow, facilitating mechanical removal. Deicing agents may be applied as either solids or in solutions with current practices favoring use of aqueous solutions.

The choice of chemicals is based upon not only the degree of freezing point depression required, but also upon how corrosive the chemical is. Salt (sodium chloride or potassium chloride) is not a suitable agent because of the significant potential for damage to aircraft due to chloride attack of metal components. Several different chemicals have been used, some of the more popular compounds being propylene and ethylene glycol, urea, potassium acetate, sodium acetate, sodium formate and calcium magnesium acetate.

Glycol- and urea-based anti-icing and deicing products were in common use on airport runways until the mid 1990's. Biodegradation of glycols consumes oxygen, imposing a high biochemical oxygen demand (BOD) ${ }^{1,2}$. In instances where the biodegradation rate is high, the concentration of dissolved oxygen (DO) in affected aquatic environments may fall below levels required to maintain life. Urea also has a high BOD due both to biodegradation and as a result of promoting algae growth with the resulting algae bloom consuming much of the available dissolved oxygen ${ }^{1,2}$. Additionally, as urea biodegrades, ammonia is formed and there is the potential for toxic ammonia concentrations to 
develop in aquatic systems receiving airport runoff ${ }^{1,2}$. Fish kills, high BOD and low DO have been reported ${ }^{1}$ and in the early 1990's, less environmentally burdensome deicers were sought. By the mid 1990's, glycol- and urea-based agents had largely been replaced by acetate- and formate-based agents, with potassium acetate (KAc) becoming the most commonly used. While less environmentally burdensome, Corsi et al. ${ }^{3}$ reported that these new chemicals still have significant negative impact on aquatic environments receiving runoff from runways and taxiways.

A few airports reported distress and premature failure of portland cement runway pavements within a few years of adopting the new deicers. The failure mechanism appeared to be similar to that of alkali-silica reactivity (ASR) with characteristic mapcracking and spalling of concrete on affected runways. Subsequent lab-scale tests employing modified standard procedures confirmed that carboxylate-based deicing products exacerbate expansion in concrete containing reactive aggregates ${ }^{4}$. Moreover, lab tests indicated that previously known innocuous aggregates could be made to produce deleterious expansion when soaked in deicer-containing solutions for a sufficient period of time. Alteration and even disintegration of cement paste was also demonstrated under the right experimental conditions ${ }^{5}$.

Because of these alarming lab results, the FAA adopted a more stringent procedure for testing aggregate considered for use in portland cement concrete pavements exposed to carboxylate deicers ${ }^{6}$. Both field observation and lab testing continued with a notable lack of evidence from the field indicating that there was indeed a problem ${ }^{7}$ while lab experiments continued to demonstrate that carboxylates caused severe expansion of concrete. Ultimately, the lack of field evidence resulted in the FAA removing the more stringent aggregate testing requirement ${ }^{8}$. Laboratory testing continues in an effort to better understand the mechanism at work and to ascertain the long term fate of portland cement pavements repeatedly exposed to carboxylate deicing chemicals.

A review of ASR is necessary to lay the foundation for the research considered herein. ASR was first reported as a material related distress in concrete by Stanton in 1940 after analyzing California bridges showing signs of deterioration ${ }^{9}$. Distress manifests itself as a 
series of interconnected cracks, called map-cracking, on the surface of unrestrained concrete structures. Reinforced concrete structures typically suffer fracturing that is parallel to internal reinforcement. In many cases, structural integrity is not impaired despite significant cracking on the surface of the member ${ }^{10}$. Positive identification of ASR requires petrographic examination of the affected concrete to determine the presence of a) known reactive aggregate, b) ruptured aggregate grains and c) silica gel ${ }^{11}$. Helmuth conducted a semi-exhaustive review of ASR research in $1993^{12}$, offering a concise overview of the understanding of ASR chemistry and the expansion mechanism. Powers and Steinour proposed an expansion model in 1955 which has served as the foundation of our understanding since. Their model is based upon the swelling of silica gels formed post-dissolution of reactive silica aggregates. The model states that the expansion potential of a silica gel is related to its chemistry. High calcium gels do not swell whereas low calcium gels are subject to significant swelling. The role of hydroxide concentration (alkali content) was also defined. With this understanding, they developed the conditions under which deleterious expansion of concrete occurs as well as means to mitigate expansion.

Three conditions are required for expansion due to ASR:

1) The presence of reactive silica aggregate in the concrete mixture. Reactive aggregates typically contain poorly ordered or completely amorphous silica minerals. Opals, cherts (flints), glassy volcanics (rhyolites containing obsidian) are common examples of reactive aggregates. Highly stressed silica and diagenetic silica in sedimentary rocks have also been found to be reactive ${ }^{9}$.

2) High $\mathrm{pH}$ pore solutions. The solution that occupies the significant pore volume within cement paste is alkaline, having a relatively high $\mathrm{pH}^{9}$. The concentration of soluble alkalis ( $\mathrm{Na}$ and $\mathrm{K}$ typically as sulfates ${ }^{9}$ ) in concrete mixtures in large part determines the $\mathrm{pH}$, with higher concentrations resulting in a higher $\mathrm{pH}$ pore solution. Portlandite $\left(\mathrm{Ca}(\mathrm{OH})_{2}\right)$ is also a potential source of hydroxyl. Hydroxyl plays a significant role in ASR chemistry via both dissolution of silica and polymerization and condensation of dissolved silica. 
3) A wet environment. Water is the solvent and the transport medium for the reactants as well as the medium in which polymerization of $\mathrm{SiO}_{2}$ and subsequent formation of gels takes place. A relative humidity in concrete of greater than $80 \%{ }^{12}$ has been reported to be necessary for ASR to progress. Under the prevailing ASR distress theory, water also plays a role in development of internal stresses as gels swell upon imbibing free water. One mitigation strategy is, where possible, to reduce the affected concrete's exposure to water.

Careful selection of aggregate has long been the first defense against ASR as only aggregates classified as "reactive" (i.e. susceptible to producing ASR expansion) result in the formation of expansive gels. Several testing methods exist for assessing the suitability of aggregate for use in portland cement concrete. The most commonly used procedures employ a methodology known as Accelerated Mortar Bar Testing (AMBT). ASTM C1260 "Standard Test Method for Potential Alkali Reactivity of Aggregates (Mortar-Bar Method)" is one such method ${ }^{13}$. Mortars are made with the aggregate to be evaluated, cast into three 11 " x 1" x 1" prisms, moist set for 24 hours then cured 24 hours in $80^{\circ} \mathrm{C}$ water and finally soaked in an alkaline solution containing $1 \mathrm{~N} \mathrm{NaOH}$ at $80^{\circ} \mathrm{C}$ for 14 days. The initial length of the mortar bar is measured after the curing period, immediately prior to placement in the soak solution. Bars are periodically removed from the solution and their lengths measured and compared to their initial lengths. Aggregate producing expansion greater than $0.2 \%$ at the end of the 14 day soaking period is considered potentially reactive. Expansion between $0.1 \%$ and $0.2 \%$ is inconclusive, warranting further testing. An aggregate is deemed innocuous if it produces expansion less than $0.1 \%$.

ASTM C289 "Standard Test Method for Potential Alkali-Silica Reactivity of Aggregates (Chemical Method)" is much less commonly employed ${ }^{14}$. It rates the potential of an aggregate to produce deleterious expansion based upon the concentration of silica and hydroxyl in solution after soaking only the aggregate in a $1 \mathrm{~N} \mathrm{NaOH}$ solution at $80^{\circ} \mathrm{C}$ for 24 hours. The method has been shown to produce results that disagree with other established methods. 
Definitive assessment of an aggregate's degree of reactivity requires testing with longer term methodologies in which expansion of concrete prisms containing the aggregate is evaluated over a 12 to 24 month period. ASTM C1293 "Standard Test Method for Determination of Length Change of Concrete Due to Alkali-Silica Reaction" is the method most commonly employed ${ }^{15}$.

Aggregate is the largest mass fraction constituent in portland cement concrete.

Contractors make every attempt to locate suitable aggregate nearby construction sites so as to minimize transportation costs. Environmental regulations and consumption has resulted in tightening aggregate supplies and concrete producers are sometimes forced to use aggregate that has been found potentially reactive. Under such circumstances, partial replacement of portland cement with a suitable supplementary cementitious material (SCM) such as fly ash or ground granulated blast furnace slag can reduce the expansion rate.

The efficacy of an SCM is determined by testing methods identical to those used for determining an aggregate's potential to produce deleterious expansion: AMBT and concrete prism methodologies. ASTM C1567 "Standard Test Method for Determining the Potential Alkali-Silica Reactivity of Combinations of Cementitious Materials and Aggregate (Accelerated Mortar-Bar Method)" is identical to ASTM C1260 except that mortars are made with known additions of SCM partially replacing portland cement in the mix ${ }^{16}$. Definitive assessment is again completed with ASTM C1293 with concrete mixtures having some replacement of portland cement by an SCM.

Another expansion mitigation strategy is to minimize alkali content in portland cement used in the mixture. The hydroxyl ion plays a key role in ASR chemistry and is present in all portland cements ${ }^{9}$. This method is less often used as cement is the highest cost component of the mixture and low alkali cement has a higher unit cost than Type I cement.

Mitigation of expansion occurring in field-emplaced concrete structures is difficult and largely centered on attempting to keep the affected structure dry. Application of lithium 
salts to affected concrete has demonstrated limited success ${ }^{17,18}$. Lithium salts are also added as an admixture to concrete mixtures containing known reactive aggregate.

Petrographic examination is required for positive identification of ASR-affected concrete. ASTM C856 "Standard Practice for Petrographic Examination of Hardened Concrete" details diagnostic criteria required for identification of $\mathrm{ASR}^{11}$. Several other documents specifically related to the transportation industry also detail detection and identification of $\mathrm{ASR}^{19-22}$. In all cases, positive identification requires the presence of aggregate having mineralogy known to produce silica gels and detection of those gels in affected concrete.

Upon petrographic examination, one frequently observed characteristic is the failure of reactive aggregate particles themselves. This is in fact a diagnostic criterion ${ }^{11}$. Affected aggregate grains rupture with fractures extending into the surrounding cement paste. This implies that expansive stress builds within the aggregate grain; the surrounding cement paste fractures only after or concurrent with grain rupture. Several attempts have been made to explain the mechanism causing rupture and expansion, virtually all are centered upon the model developed in 1955, focusing on the nature of expansive silica gels.

Prezzi et al. posited that expansive forces develop as a result of the electrical double layer that forms on the highly charged surface of silica gels ${ }^{23}$. The theory essentially states that the large electrical charge on the surface of silica gels causes redistribution of ions and polar molecules in contact with the gel such that pressure is exerted on the surrounding pore fluids, in effect reducing the density of the fluid. Rodrigues, et al. measured the surface proton charge density on various silica species at different $\mathrm{pH}$ with both $\mathrm{Na}^{+}$and $\mathrm{K}^{+}$and concluded that expansive pressure caused by the electrical double layer was highly influenced by $\mathrm{pH}$ but less so by the alkali and alkaline species ${ }^{24,25}$. While this work was intended to test the double layer pressure theory, it was in fact a repeat of work performed by Iler et al. ${ }^{26}$ and may have been misguided in that Prezzi's premise was based upon the double layer present with silica gel products from dissolution of aggregate, whereas Rodriguesperformed the test on the aggregate itself. 
Ichikawa et al. disputed Prezzi's premise, stating that the force generated by an electrical double layer in hydrated cement paste is negligible ${ }^{27}$. They offered an alternative theory commonly known as the "jawbreaker" model in which expansive pressure is a function of the rigidity of silica gel formed after dissolution and that encases the reacting aggregate particle. Fracturing of glass beads was induced by successively soaking beads first in a sodium hydroxide solution, then a calcium hydroxide solution and then again in sodium hydroxide. They surmised that initial dissolution of silica in the sodium solution resulted in a coating of silica gel that was then converted to calcium silicate upon soaking in calcium hydroxide. The calcium silicate coating did not stop transport of hydroxide into the unreacted core, but was sufficiently thick and rigid to block egress of dissolving silica. The dissolution of silica therefore continued when the beads were placed into the $\mathrm{NaOH}$ solution again and pressure built within the dissolving glass bead, only to be released by fracturing of the bead and rigid surrounding shell. Ichikawa later explained the pessimum and pozzolonic effects using the jawbreaker model ${ }^{28}$.

Taguchi et al. examined the effect of various anions and cations on the rate of ASR reaction with Japanese aggregates known to be reactive ${ }^{29}$. They found no conclusive evidence that the reaction rate was affected by ionic species.

Hou et al. investigated reactions between alkalis, reactive silica and C-S-H gels. Results from their research support the original theory with regards to the role of calcium and hydroxide on the pozzolonic or gel reactions that occur. They found that $\mathrm{K}^{+}$reacts with silica at a higher rate than does $\mathrm{Na}^{+30}$.

The application of salts to pavements for the purposes of deicing has long been suspected of exacerbating ASR-induced expansion and have therefore been the subject of several research efforts ${ }^{12,29,31-35}$. Potassium acetate has of late become the deicing agent garnering the greatest amount of interest due to the issues reported by a few airports using it. 
The Innovative Pavement Research Foundation (IPRF) commissioned research into the potential for ASR exacerbation in the presence of airfield deicers (IPRF Project 01-G002-03-9). The final report ${ }^{36}$ was released in March of 2007.

The researchers utilized an experimental method based upon ASTM C1260 to examine the potential effects of KAc on concrete. The modified ASTM C1260 method developed by Rangaraju et al. ${ }^{36}$ consists of soaking mortar bars in formate- and acetate-based deicer solutions of different concentrations at $80^{\circ} \mathrm{C}$ and comparing expansion to that caused by soaking in $1 \mathrm{~N} \mathrm{NaOH}$. Cements of different alkali content were tested with highlyreactive, moderately-reactive and non-reactive aggregates. They concluded that the deicer solutions in all cases accelerated ASR in mixes containing even moderately reactive aggregates. Potassium acetate proved to be the most aggressive of the deicing agents, causing the greatest amount of expansion in mortars made with highly-reactive aggregate. Mortars made with high alkali cements expanded more rapidly than those with low alkali cements. Mortars made with non-reactive aggregate did not expand significantly in any of the solutions.

The researchers made particular note of odd $\mathrm{pH}$ and hydroxyl concentrations in pore solutions:

"The results of the $\mathrm{OH}^{-}$analysis were rather surprising. To start with, the $\mathrm{pH}$ values determined by conventional glass-electrode standardized to calcium hydroxide showed much higher values than indicated by the titration results. In point of fact, the titration indicated that the concentrations of $\mathrm{OH}^{-}$ions (in case of concretes soaked in potassium acetate deicer solution) were very low - between 0.030 and $0.060 \mathrm{M}$. This is not the concentration range which would be able to cause ASR in terms of the conventional mechanism of this reaction. For sodium acetate and sodium formate deicer solutions, the indicated concentrations of hydroxyl ions by titration were somewhat higher, but they were also far below the concentration considered necessary for triggering the ASR. The only exception was the pore solution of the concretes soaked in sodium formate for 6 months, where the $\mathrm{OH}^{-}$ions concentration was estimated by the titration to be about 500 $\mathrm{mM}$. What is even more unusual, these values were substantially lower than those expected for normal concrete. It is also worth noting that the indicated differences between the hydroxyl ions concentrations for different aggregates were far less than the concentration differences between average concentrations for different soak solutions. The indicated hydroxyl ion concentration in sodium hydroxide soak solution were far higher than those of the deicer solutions and were, as 
expected, in the range considered as a potentially dangerous for reactive aggregates." 36

Further testing with just the deicing solutions showed that $\mathrm{pH}$ increased dramatically and unexpectedly with the addition of portlandite $\left(\mathrm{Ca}(\mathrm{OH})_{2}\right)$. They concluded:

"Although the hydroxyl ion concentrations estimated by titration for the pore solutions of concretes soaked in deicer solutions are very low, the evidences of concrete deterioration are very significant. These factors suggest that the mechanism of this kind of deterioration might be different in some respects from that commonly encountered for typical ASR."36

An explanation for the sharp increase in measured $\mathrm{pH}$ upon addition of portlandite to deicer solutions was provided by Stark and Giebson ${ }^{37}$ who found that the solubility of portlandite increased in the presence of acetate and formate as a result of calcium complexation. They apparently did not attempt to measure hydroxyl concentration directly but instead measured $\mathrm{pH}$ with an alkali-resistant $\mathrm{pH}$ probe ${ }^{37}$.

Research for another IPRF project (IPRF-01-G-002-04-8) "Mitigation of ASR in Presence of Pavement Deicing Chemicals"38 utilized ASTM C1567 to identify possible mitigation strategies. The researchers restated that ASR-like failure occurred only when reactive aggregates were present and that bars soaked in deicer suffered significantly increased expansion as compared to the $\mathrm{NaOH}$ control. The addition of low or intermediate lime fly ash and ground, granulated blast furnace slag at sufficient cement replacements (25\%-35\% for FA, 50\% for GGBFS) was found to effectively mitigate the ASR-like expansion, as was lithium nitrate ${ }^{38}$.

In summary, these last two research efforts made the following key conclusions:

1. ASR-like expansion is produced in mortar bars containing any reactive aggregates soaked in deicer solutions. The expansion resembles that observed in similar bars soaked in $\mathrm{NaOH}$, but the degree of expansion is dependent upon the deicer compound and the nature of the reactive aggregate. Bars soaked in potassium acetate suffer the greatest expansion.

2. Bars containing non-reactive aggregate soaked in deicers or $\mathrm{NaOH}$ show no appreciable expansion. 
3. Mitigation is possible with partial replacement of cement with SCM's. 


\section{Goals and Hypotheses}

The goals of this research are:

1. Verify that potassium acetate exacerbates ASR-expansion under AMBT conditions.

2. Verify that mitigation of KAc-exacerbated ASR-expansion is possible with partial replacement of cement with suitable SCMs.

3. Ascertain the role of SCM chemistry, in particular calcium content, in mitigation potential.

4. Determine if the type of alkali hydroxide $(\mathrm{NaOH}$ or $\mathrm{KOH})$ has an effect on expansion rate.

5. Evaluate mortars petrographically after soaking in the various solutions.

Other researchers have opined the process resulting in KAc-exacerbated expansion is somehow different than that of "normal" ASR. It is the intent of this research to demonstrate that the processes are indeed identical and that KAc only acts to increase the rate of expansion. 


\section{Methods}

ASTM C1260 "Standard Test Method for Potential Alkali Reactivity of Aggregates (Mortar-Bar Method)" and ASTM C1567 "Standard Test Method for Determining the Potential Alkali-Silica Reactivity of Combinations of Cementitious Materials and Aggregate (Accelerated Mortar-Bar Method)" tests were performed according to the experimental matrix shown in Table 3.1. The procedures were modified to include two additional soak solutions, $1 \mathrm{~N} \mathrm{NaOH}$ in $3.2 \mathrm{M} \mathrm{KAc}$ and $1 \mathrm{~N} \mathrm{KOH}$ in $3.2 \mathrm{M} \mathrm{KAc}$.

Aggregates having produced expansion at varying rates were selected for testing. Ottawa sand was chosen as the non reactive aggregate, Sioux quartzite is a moderately reactive aggregate and Spratt limestone the most reactive aggregate. Two additional aggregates were evaluated with the ASTM C1260 methods; a non-reactive local amygdaloidal basalt and a synthetic reactive aggregate having borosilicate glass making up the $-50+100$ mesh fraction of an otherwise all Ottawa sand aggregate.

All solutions were maintained at $80^{\circ} \mathrm{C}$ for the duration of the soaking period. The entire test matrix was subjected to soak durations of 14 days. Fly ash used in the ASTM C1567 experiments was selected based upon calcium content. Both ASTM Type $\mathrm{C}$ and $\mathrm{F}$ ashes were investigated and their properties are shown in Table 3.2. $\mathrm{Na}_{2} \mathrm{O}_{\mathrm{e}}$ in Table 3.2 is the total alkali content ( $\mathrm{Na}$ and $\mathrm{K}$ ) expressed as $\mathrm{Na}_{2} \mathrm{O}$ equivalent. 
Table 3.1

AMBT test matrix.

\begin{tabular}{c|ccc}
\multirow{2}{*}{$\begin{array}{c}\text { SCM replacement rate and } \\
\text { type }\end{array}$} & \multicolumn{3}{|c}{ Soak solutions } \\
\cline { 2 - 4 } & 1N NaOH & 1N NaOH in & 1N KOH in \\
& Spratt, Sioux & Spratt, Sioux & Spratt, Sioux \\
$30 \%$ high Ca & Spratt, Sioux & Spratt, Sioux & Spratt, Sioux \\
$15 \%$ mid Ca (F1) & Spratt, Sioux & Spratt, Sioux & Spratt, Sioux \\
$30 \%$ mid Ca (F1) & Spratt, Sioux & Spratt, Sioux & Spratt, Sioux \\
$15 \%$ mid Ca (F2) & Spratt, Sioux & Spratt, Sioux & Spratt, Sioux \\
$30 \%$ mid Ca (F2) & Spratt, Sioux & Spratt, Sioux & Spratt, Sioux \\
$15 \%$ low Ca & Spratt, Sioux & Spratt, Sioux & Spratt, Sioux \\
$30 \%$ low Ca & Spratt, Sioux & Spratt, Sioux & Spratt, Sioux \\
$40 \%$ ground granulated & Spratt, Sioux & Spratt, Sioux & Spratt, Sioux \\
blast furnace slag & Spratt, Sioux, & Spratt, Sioux, & Spratt, Sioux, \\
& Ottawa, Synthetic & Ottawa, Synthetic & Ottawa, Synthetic \\
reactive, Local & reactive, Local & reactive, Local \\
No SCM (ASTM C1260) & basalt & basalt & basalt
\end{tabular}


Table 3.2

Properties of fly ash.

ASTM Type

Retained on \#325 sieve

(\%)

Density $\left(\mathrm{g} / \mathrm{cm}^{3}\right)$

LOI

$\mathrm{Na}_{2} \mathrm{O}_{\mathrm{e}}(\%)$

Available alkali (as

$\% \mathrm{Na}_{2} \mathrm{O}_{\mathrm{e}}$ )

$\mathrm{SiO}_{2}(\%)$

$\mathrm{Al}_{2} \mathrm{O}_{3}(\%)$

$\mathrm{Fe}_{2} \mathrm{O}_{3}(\%)$

$\mathrm{CaO}(\%)$

$\mathrm{MgO}(\%)$

$\mathrm{SO}_{3}(\%)$

\begin{tabular}{cccc} 
Low Ca & Mid Ca $(\mathrm{F} 1)$ & Mid Ca $(\mathrm{F} 2)$ & High Ca \\
\hline $\mathrm{F}$ & $\mathrm{F}$ & $\mathrm{F}$ & $\mathrm{C}$ \\
15.80 & 23.60 & 25.70 & 10.90 \\
2.43 & 2.48 & 2.41 & 2.71 \\
2.19 & 0.45 & 1.43 & 0.20 \\
2.16 & 1.94 & 2.04 & 2.39 \\
0.81 & 0.89 & 0.73 & 1.58 \\
62.44 & 44.81 & 58.92 & 30.81 \\
20.07 & 23.08 & 16.17 & 17.57 \\
6.95 & 9.51 & 4.71 & 5.87 \\
1.81 & 13.58 & 10.24 & 29.21 \\
1.33 & 2.97 & 3.13 & 7.64 \\
0.32 & 0.96 & 0.86 & 3.25
\end{tabular}




\section{Results}

\section{AMBT Results}

Expansion curves from ASTM C1260 tests are shown in Figures 4.1 through 4.3. Figure 4.1 and Figure 4.2 show expansion curves grouped by aggregate type to demonstrate the effect of solution chemistry on expansion rate. Figure 4.3 shows the expansion curves for all aggregate types grouped by solution chemistry, effectively ranking the aggregates by their respective expansion rates.

Figures Figure 4.4 through Figure 4.7 are expansion curves for ASTM C1567 experiments performed with fly ash and are grouped by solution chemistry so as to facilitate visualization of the effect fly ash calcium concentration has on mitigation potential of the SCM. Figures 4.8 and 4.9 are expansion curves for ASTM C1567 experiments with $40 \%$ replacement of portland cement with ground granulated blast furnace slag. 
$-1 \mathrm{~N} \mathrm{NaOH}-1 \mathrm{~N} \mathrm{NaOH}$ in $3.2 \mathrm{M} \mathrm{KAc}-1 \mathrm{~N} \mathrm{KOH}$ in $3.2 \mathrm{M} \mathrm{KAc}$
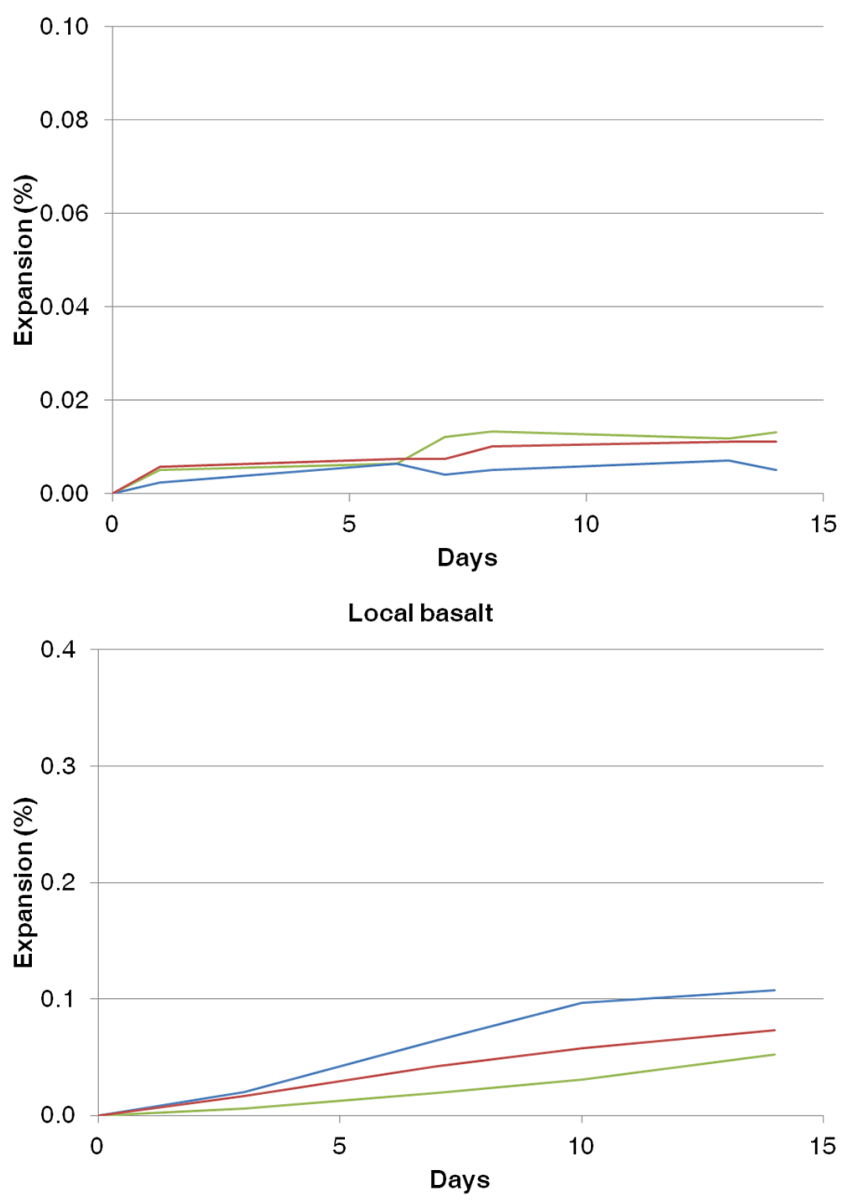

Figure 4.1: ASTM C1260 expansion curves for Ottawa sand and local basalt mortars. 


\section{$-1 \mathrm{~N} \mathrm{NaOH}$}

\section{$-1 \mathrm{~N} \mathrm{NaOH}$ in $3.2 \mathrm{M} \mathrm{KAc}-1 \mathrm{~N} \mathrm{KOH}$ in $3.2 \mathrm{M} \mathrm{KAc}$}
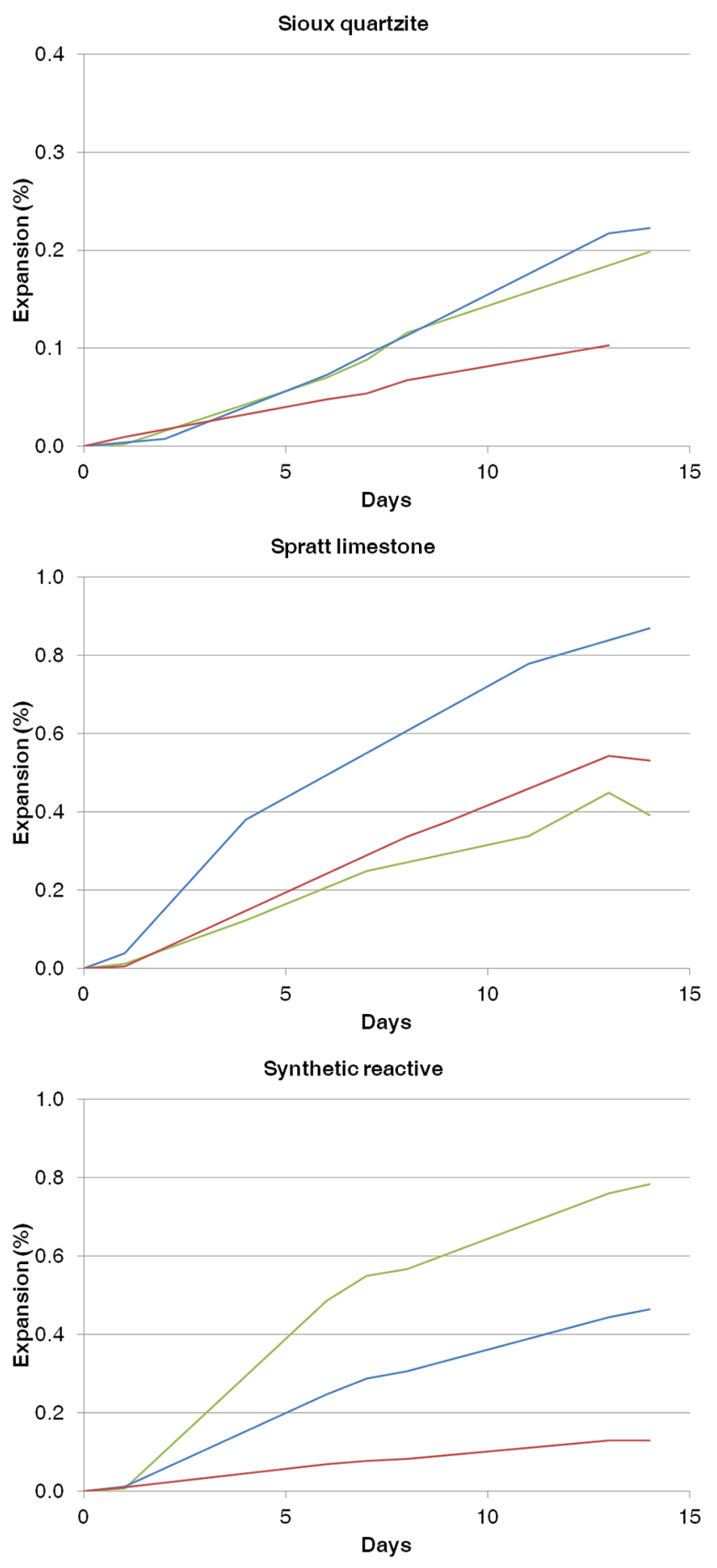

Figure 4.2: ASTM C1260 expansion curves for Sioux quartzite, Spratt limestone and synthetic reactive aggregate mortars. 
$\diamond$ Ottawa sand $\boxminus$ Synthetic reactive $\triangle$ Sioux quartzite $*$ Spratt limestone $*$ Local basalt
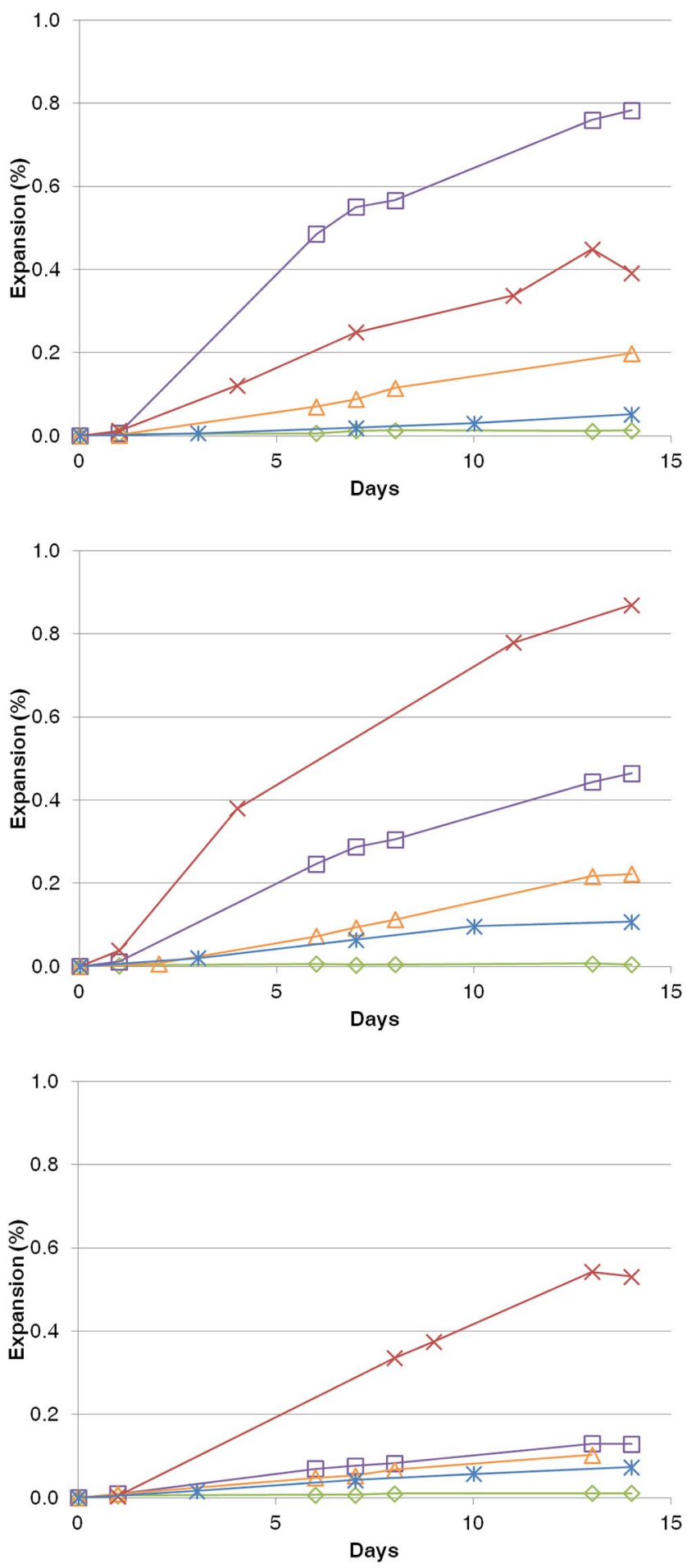

Figure 4.3: ASTM C1260 expansion grouped by soak solution. Solutions from top to bottom: $1 \mathrm{~N}$ $\mathrm{NaOH}, 1 \mathrm{~N} \mathrm{NaOH}$ in $3.2 \mathrm{M} \mathrm{KAc}, 1 \mathrm{~N} \mathrm{KOH}$ in $3.2 \mathrm{M} \mathrm{KAc}$. 
$*$ No SCM $=1.81 \% \mathrm{Ca} \star 10.24 \% \mathrm{Ca} \nrightarrow 13.58 \% \mathrm{Ca}-29.21 \% \mathrm{Ca}$
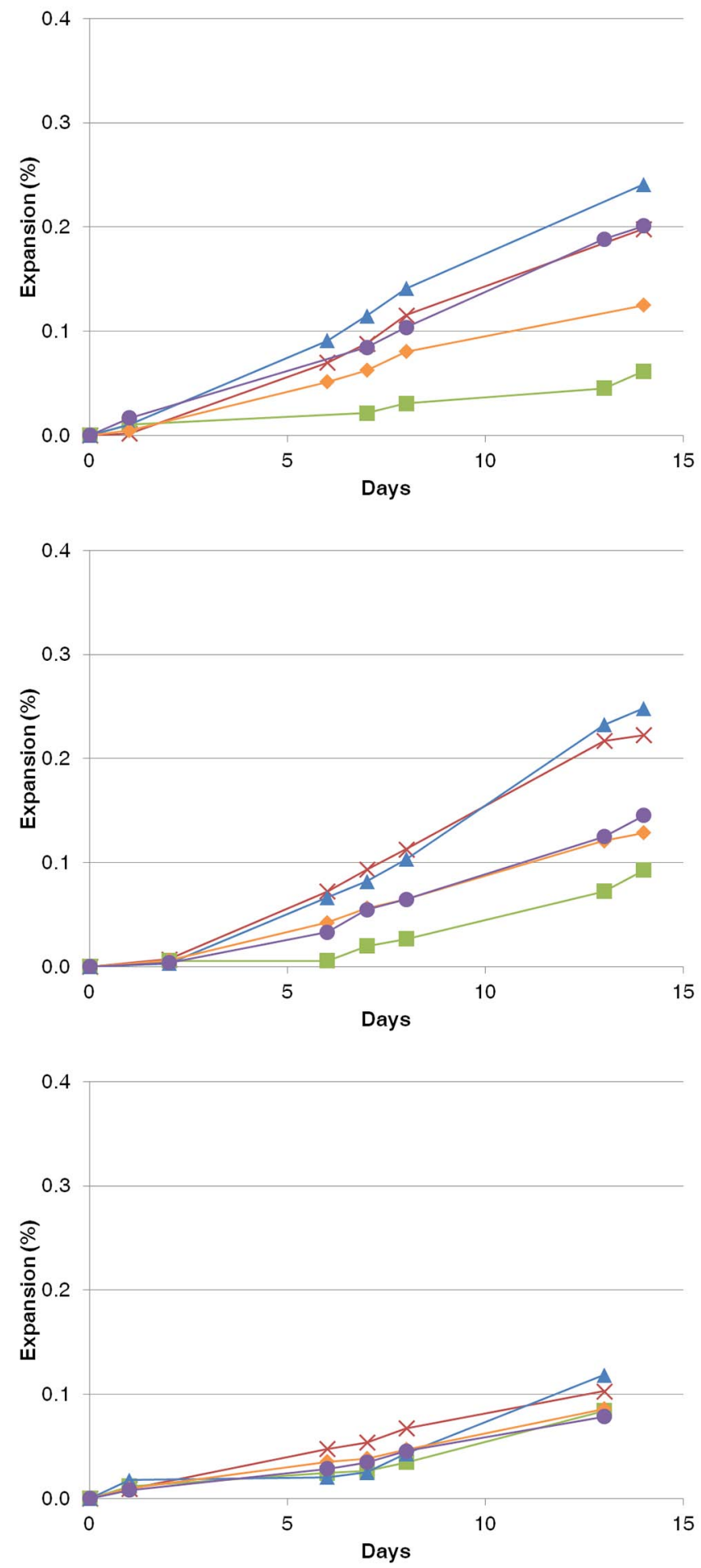

Figure 4.4: $\mathrm{C} 1567$ expansion rate curves with Sioux quartzite and a 15\% replacement rate with fly ash. Solutions from top to bottom: $1 \mathrm{~N} \mathrm{NaOH}, 1 \mathrm{~N} \mathrm{NaOH}$ in $3.2 \mathrm{M} \mathrm{KAc}, 1 \mathrm{~N} \mathrm{KOH}$ in $3.2 \mathrm{M}$ KAc. 


\section{$*$ No SCM $=1.81 \% \mathrm{Ca} \star 10.24 \% \mathrm{Ca} \nrightarrow 13.58 \% \mathrm{Ca}-29.21 \% \mathrm{Ca}$}
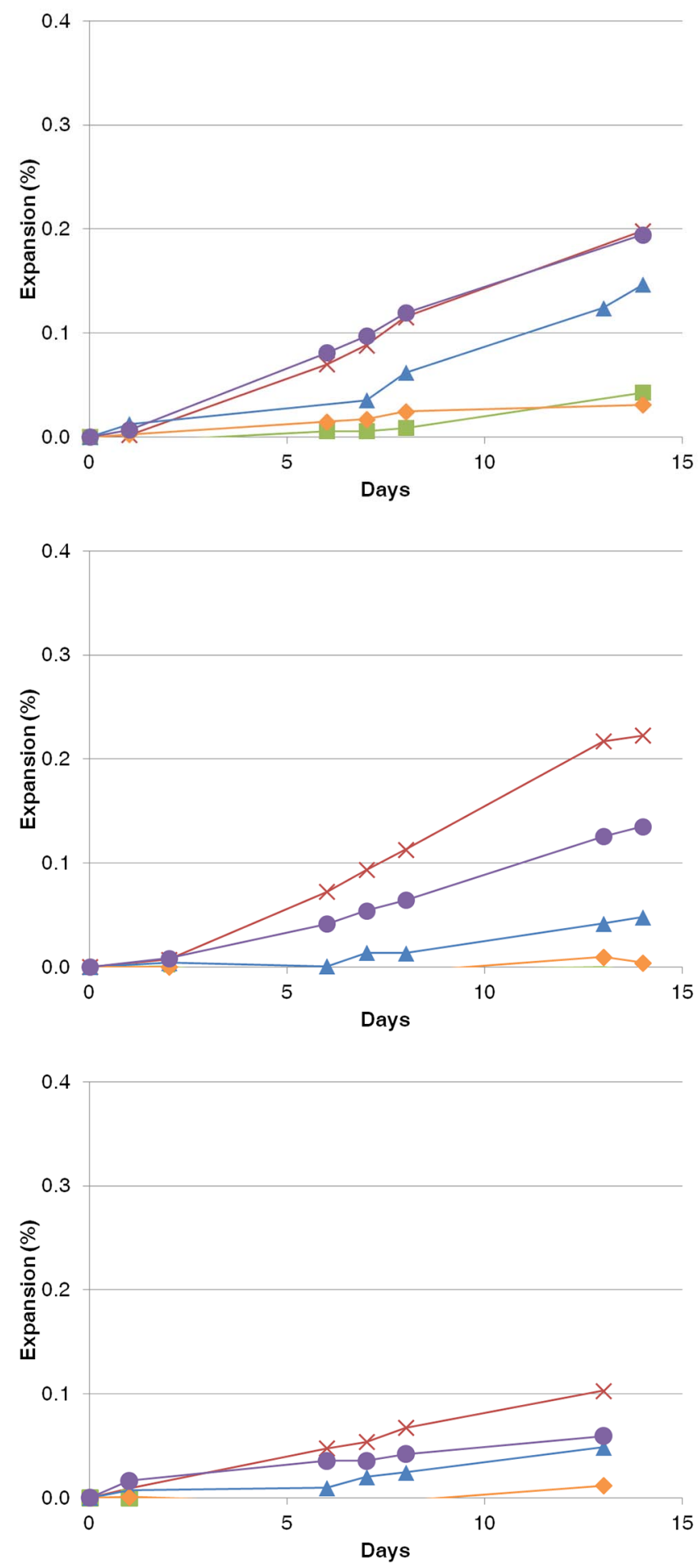

Figure 4.5: C1567 expansion rate curves with Sioux quartzite and a 30\% replacement rate with fly ash. Solutions from top to bottom: $1 \mathrm{~N} \mathrm{NaOH}, 1 \mathrm{~N} \mathrm{NaOH}$ in $3.2 \mathrm{M} \mathrm{KAc}, 1 \mathrm{~N} \mathrm{KOH}$ in $3.2 \mathrm{M}$ KAc. 


\section{$*$ No SCM $=1.81 \% \mathrm{Ca} \star 10.24 \% \mathrm{Ca} \nrightarrow 13.58 \% \mathrm{Ca}-29.21 \% \mathrm{Ca}$}
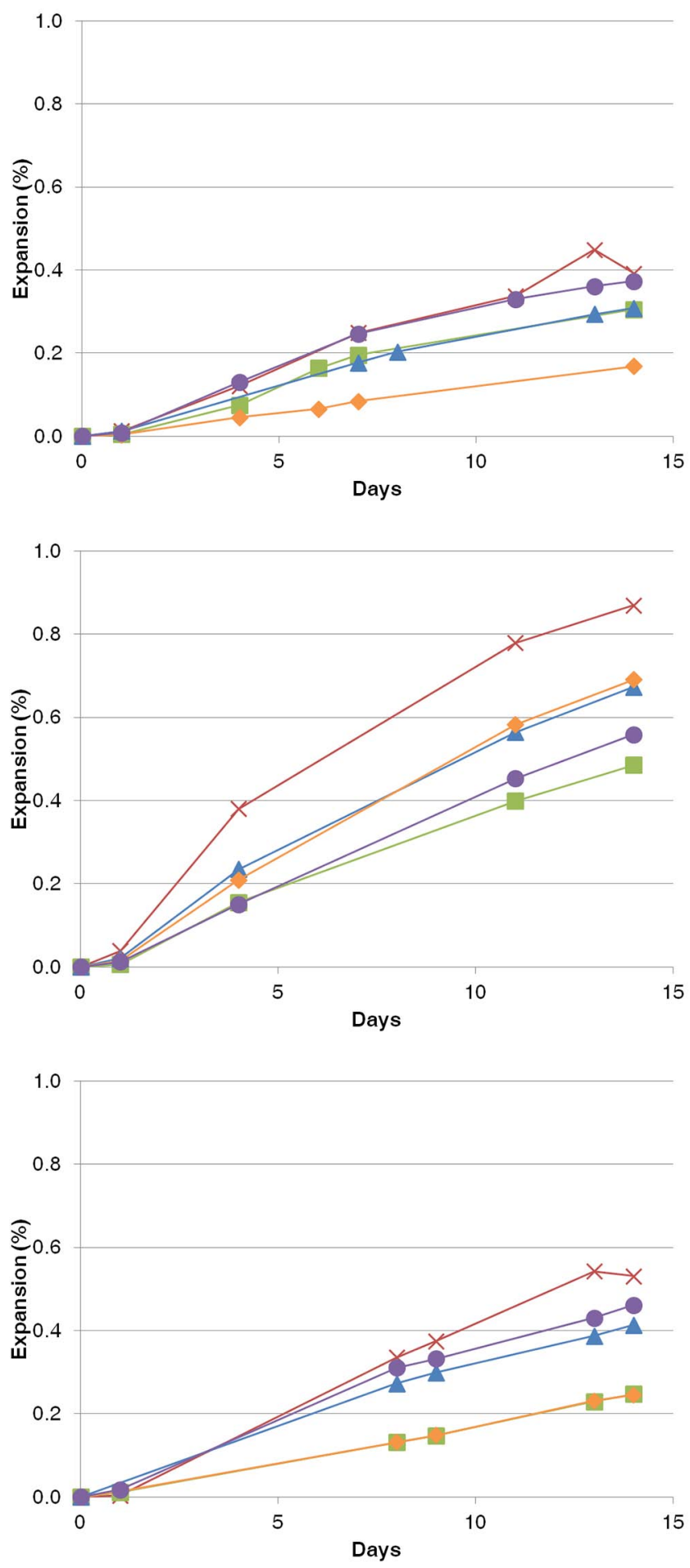

Figure 4.6: C1567 expansion rate curves with Spratt limestone and a 15\% replacement rate with fly ash. Solutions from top to bottom: $1 \mathrm{~N} \mathrm{NaOH}, 1 \mathrm{~N} \mathrm{NaOH}$ in $3.2 \mathrm{M} \mathrm{KAc}, 1 \mathrm{~N} \mathrm{KOH}$ in $3.2 \mathrm{M}$ KAc. 


\section{$*$ No SCM $=1.81 \% \mathrm{Ca} \star 10.24 \% \mathrm{Ca} \nrightarrow 13.58 \% \mathrm{Ca}-29.21 \% \mathrm{Ca}$}
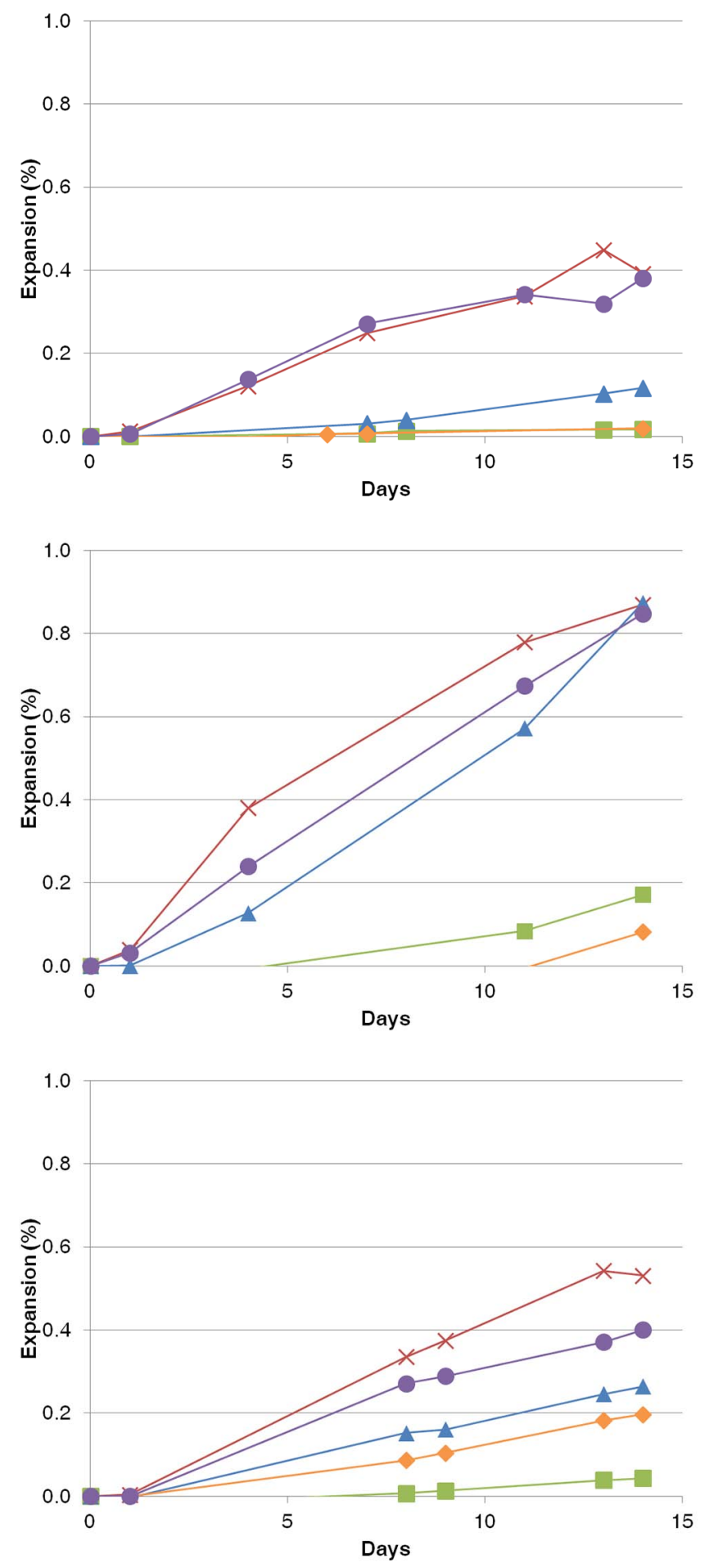

Figure 4.7: C1567 expansion rate curves with Spratt limestone and a 30\% replacement rate with fly ash. Solutions from top to bottom: $1 \mathrm{~N} \mathrm{NaOH}, 1 \mathrm{~N} \mathrm{NaOH}$ in $3.2 \mathrm{M} \mathrm{KAc}, 1 \mathrm{~N} \mathrm{KOH}$ in $3.2 \mathrm{M}$ KAc. 
$-40 \%$ GGBFS *No SCM
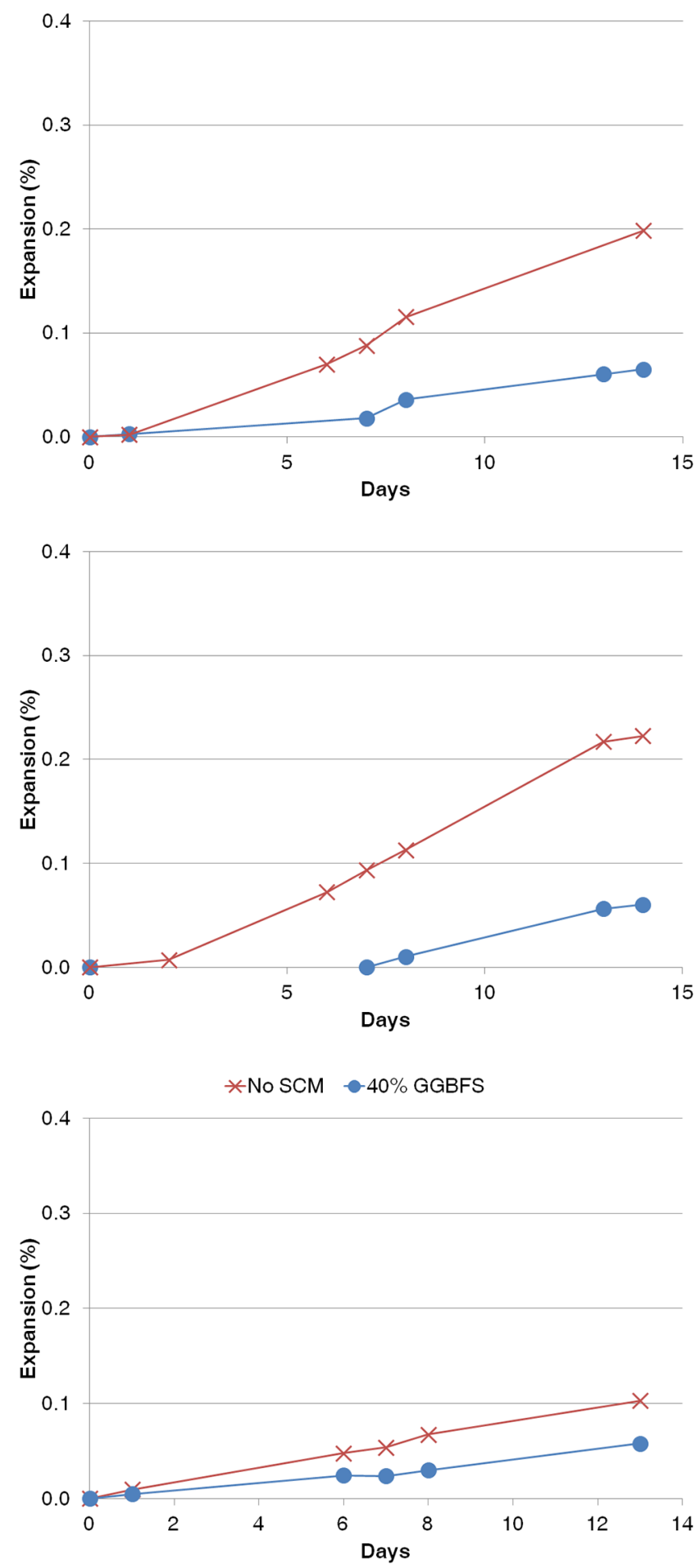

Figure 4.8: C1567 expansion rate curves with Sioux quartzite and a 40\% replacement rate with ground granulated blast furnace slag. Solutions from top to bottom: $1 \mathrm{~N} \mathrm{NaOH}, 1 \mathrm{~N} \mathrm{NaOH}$ in $3.2 \mathrm{M}$ $\mathrm{KAc}, 1 \mathrm{~N} \mathrm{KOH}$ in $3.2 \mathrm{M} \mathrm{KAc}$. 


\section{$-40 \%$ GGBFS $*$ No SCM}
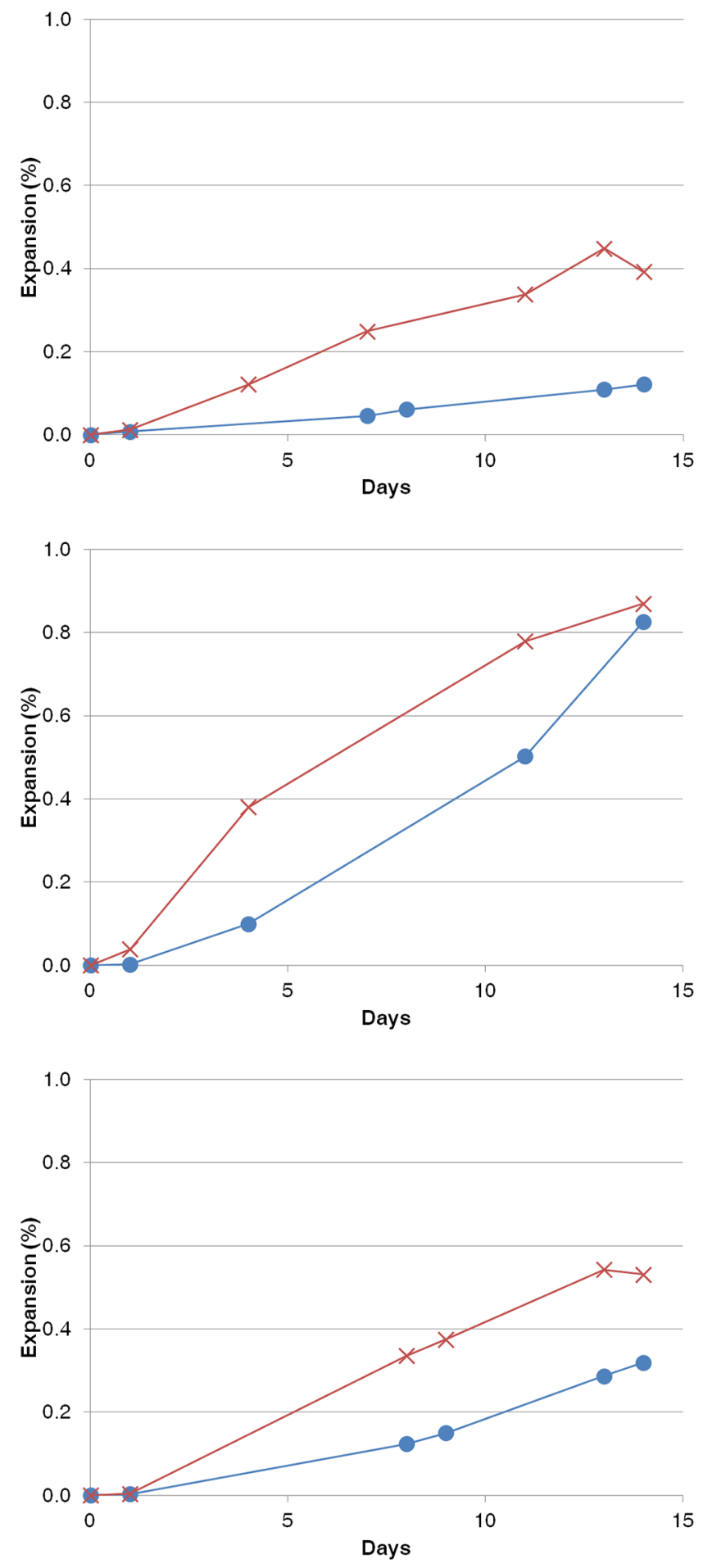

Figure 4.9: C1567 expansion rate curves with Spratt limestone and a 40\%replacement rate with ground granulated blast furnace slag. Solutions from top to bottom: $1 \mathrm{~N} \mathrm{NaOH}, 1 \mathrm{~N} \mathrm{NaOH}$ in $3.2 \mathrm{M}$ $\mathrm{KAc}, 1 \mathrm{~N} \mathrm{KOH}$ in $3.2 \mathrm{M} \mathrm{KAc}$. 


\section{Petrographic examination of AMBT specimens}

Cross sections were cut from AMBT bars and vacuum impregnated with fluorescentdyed epoxy. Thin sections were then prepared and observed with a petrographic microscope. All sample preparation was performed anhydrously so as to minimize disturbance of water soluble and hydrated products common in portland cement mortars. For the purposes of this comparison, only micrographs of mortars soaked in NAOHcontaining solutions are evaluated.

Epifluorescent illumination was used to highlight the nature of porosity (density) and cracks and voids in the mortars and aggregate particles they contain. This method capitalizes on the fluorescent nature of the dyed epoxy used to impregnate the specimens. Under reflected near-UV spectrum illumination, the dye fluoresces bright green. Vacuum impregnation helps assure that voids are completely filled with epoxy, making even the finest void and fracture features visible when properly illuminated. Subtle variations in porosity are clearly apparent with less porous (dense) areas fluorescing less intensely than areas having grater porosity. Open voids and fractures fluoresce very intensely as they possess the highest epoxy concentration.

Figures 4.10 through 4.13 are low magnification micrographs of the edges of mortar bars soaked in $1 \mathrm{~N} \mathrm{NaOH}$ (left columns) and $1 \mathrm{~N} \mathrm{NaOH}$ in 3.2M KAc (right columns). Mortar bar edges are towards the left side of each image. Illumination conditions for all sets of images are, from top to bottom, epifluorescent, plane polarized light and cross polarized light. Magnification is uniform for all of the images.

In order to facilitate discrimination of the different phases in the optical micrographs, the top, left image in Figure 4.10 is annotated with explanations following. Very bright areas in epifluorescent images indicate complete infusion of the dyed epoxy. Large voids, such as that marked by the letter $\mathrm{A}$ in Figure 4.10 are air voids, bubbles, that are completely filled with fluorescent epoxy. Cracks also fluoresce very brightly. Low porosity areas, such as the very dense Ottawa sand grain marked with the letter B in Figure 4.10, contain no voids capable of being filled with epoxy and are therefore very dark to black.

Likewise, materials having very low permeability will impede diffusion of the dyed 
epoxy into voids that may be present in the structure will also fluoresce less and show up as dark areas under epifluorescent illumination.

Cement paste and many aggregates are sufficiently porous and permeable that epoxy will fill all of the voids and pores in the full thickness of a thin section. Under epifluorescent illumination, cement and aggregate grains fluoresce at an intensity relative to their concentration of epoxy; the greater the porosity, the higher the epoxy concentration, producing a greater fluorescence intensity. The arrow marked by the letter $\mathrm{C}$ in Figure 4.10 indicates an area of cement paste near the edge of the mortar bar that is denser (less porous) than paste nearer the interior of the bar, indicated by the arrow marked with the letter D (more porous cement paste). These variations in density will be noted throughout the discussion and the reader's attention should be drawn to the relative fluorescence intensity of the areas of cement paste being discussed.

Micrographs taken under plane polarized light and cross polarized light illumination conditions are also provided. Plane polarized light illumination is the condition in which light is first passed through a polarizing filter before transmission through the thin section. The polarizing filter passes only light waves oscillating in parallel planes. This lighting condition yields images of the minerals in thin section with their "normal" transmitted color.

Cross polarized illumination places an additional polarizing filter in the light path between the objective and ocular that is oriented $90^{\circ}$ to the other polarizing filter. Under these conditions, if one were to look through the microscope with no specimen in the light path only a dark gray disk would be observed as the two polarizing filters would block all of the light; a condition known as "extinction". Isotropic minerals exhibit only extinction (they appear opaque) under cross polarized illumination whereas anisotropic minerals are birefringent, splitting a single light ray into two different rays oscillating at $90^{\circ}$ to each other. As a result, rotating anisotropic minerals through the light path results in them changing from opaque (extinct) to transparent at 90 degree intervals. 
The area marked with the letter A in the middle and bottom images in the left column of Figure 4.10 is the same air void marked $\mathrm{A}$ in the epifluorescent image and demonstrates the isotropic nature of the epoxy that fills that air void: Under plane polarized illumination, the void appears green-yellow whereas under cross polarized illumination it appears opaque. Area B in the lower two images is the same Ottawa sand quartz grain marked B in the top image rotated so as to not be extinct. The grain marked by the letter $\mathrm{E}$ demonstrates a quartz grain showing various levels of extinction. Completely extinct quartz grains are apparent upon comparing the images captured under the two different illumination conditions.

Particular note will be made of the isotropic nature of the reaction products causing the densification of cement paste. This is demonstrated by the fact that under plane polarized illumination the cement paste appears relatively transparent, becoming more opaque under cross polarized illumination.

Higher magnification images highlighting areas around aggregate particles are shown in Figures 4.14 through 4.17. Illumination conditions follow the same order as stated above.

\section{Paste alteration}

Densification is used herein to denote the partial filling of the cement paste pore system with a reaction product. This densification reduces cement paste porosity, causing it to fluoresce at a lower intensity under epifluorescent illumination. All of the specimens showed some degree of paste densification that typically diminished with increasing distance from the edge of the mortar bar.

Densification of paste resulted in less contrast between paste and aggregate under all illumination conditions. Affected images exhibit lower contrast and appear washed out in comparison to images of mortars having less paste densification.

In all of the mortars, the material causing densification is isotropic; there is no birefringence evident. This fact eliminates desiccated $\mathrm{NaOH}, \mathrm{KOH}$ or $\mathrm{KAc}$ as the compound causing densification. The conclusion is therefore that the compound is the result of a chemical reaction taking place in the mortar. 
Discussions of each set of figures follows.

\section{Ottawa sand}

Figure 4.10 shows a series of micrographs of mortar bars made with Ottawa sand, which experienced no measurable expansion in the ASTM C1260 experiments. Images captured under epifluorescent illumination (top row) show slight densification of the paste in the bar soaked in $1 \mathrm{~N} \mathrm{NaOH}$. Paste in the bar soaked in the KAc solution is denser overall with no appreciable change in densification with distance from the edge of the bar, implying that the solution quickly and thoroughly penetrated the bar.

There is a paste densification gradient in relation to distance from aggregate grains. This is clearly apparent in Figure 4.10, top, right with a leopard spot-like ring pattern around aggregate grains. It is also apparent in Figure 4.14 top, left indicating the nature of paste densification is similar between the two solutions. The overall degree of densification is less in the mortar soaked in $1 \mathrm{~N} \mathrm{NaOH}$, suggesting that there is a difference in reaction rate between the two solutions.

\section{Synthetic reactive aggregate (SRA)}

Bars made with borosilicate glass and Ottawa sand are shown in Figures 4.11 and 4.15. These bars expanded at a rate approaching that of Spratt limestone but reacted differently in the solutions: SRA mortars produced the greatest expansion rate in $1 \mathrm{~N} \mathrm{NaOH}$ whereas Spratt limestone mortars produced the greatest rate in $1 \mathrm{~N} \mathrm{NaOH}$ in $3.2 \mathrm{M} \mathrm{KAc}$.

Glass particles were completely dissolved near the edge, appearing as very bright, angular voids in the images captured under epifluorescent illumination in Figure 4.11 and marked by the letter A. The area marked by letter B indicates a large fracture winding between two grains of Ottawa sand.

Paste near the edge of the bar soaked in KAc solution is denser than similarly located paste in the bar soaked in $1 \mathrm{~N} \mathrm{NaOH}$. The depth of the affected area is roughly the same in both bars, indicating that the penetration rate of solution into the bars was roughly equivalent. A similar paste density gradient with respect to distance from aggregate grains is apparent. Comparing the SRA mortars to Ottawa sand mortars, both solutions 
appear to have diffused further into the Ottawa sand mortars as indicated by the paste densification that occurred deep in the Ottawa sand mortar bars.

\section{Spratt limestone}

Micrographs of bars made with Spratt limestone are shown in Figures 4.12 and 4.16. The bar soaked in the solution containing KAc deicer has significantly more reaction product filling the paste pore system, especially near the edge of the beam. Paste within two to three millimeters of the edge is completely infused with reaction product. The paste has become so dense that distinguishing aggregate particles from paste is difficult.

A density gradient with distance from the edge of the bar is apparent in Figure 4.12. Paste density is highest near fractures as shown in Figure 4.16. Paste density also increases in a spotty fashion around the aggregate grain with areas in which no densification is apparent immediately adjacent the grain. Paste densification occurs where fractures intercept both aggregate grain and paste. For example, it is almost impossible to distinguish aggregate from paste in the plane polarized light illuminated images in Figure 4.16. Only under cross polarized illumination do the aggregate grains become apparent.

\section{Sioux quartzite}

Micrographs of Sioux quartzite mortar thin sections are shown in Figures 4.13 and 4.17. The reactive (more readily soluble) phase is the silica cement between quartz clasts. This is most clearly apparent in images captured under epifluorescent illumination where sinuous bright paths resembling fractures (marked with the letter A) can be seen passing through larger aggregate grains near the edge of the bar. Cement paste in mortar soaked in $1 \mathrm{~N} \mathrm{NaOH}$ in $3.2 \mathrm{M} \mathrm{KAc}$ is much denser than that found in mortar soaked in $1 \mathrm{~N} \mathrm{NaOH}$. The reaction product causing densification has greater transparency under plane polarized light illumination in the bar soaked in $\mathrm{KAc}$ as compared to the bar soaked in only $\mathrm{NaOH}$.

As illustrated in Figure 4.17, densification of paste is generally more uniform with a gradient appearing around only some of the aggregate grains. 


\section{Fractures}

Fracturing occurred only in mortars that produced measurable expansion and two distinct modes of failure are apparent. Spratt limestone demonstrated the failure mode frequently encountered in field-emplaced concrete suffering ASR distress, with fracturing initiated at ruptured aggregate grains and extending into the cement matrix. The second mode of failure occurred in mortars containing synthetic reactive aggregate, where fracturing was limited to only the cement paste; no ruptured aggregate grains were apparent.

\section{Ottawa sand}

No fractures are evident in paste or aggregate in Figures 4.10 or 4.14.

\section{Synthetic reactive aggregate}

Fractures apparent in Figures 4.11 (marked by the letter B) and 4.15 are limited to only the cement paste; there are no ruptured aggregate grains and fractures do not appear to initiate at aggregate grains. Instead, fractures extend through cement paste, wrapping around larger aggregate grains. Fractures also appear to be sub-parallel to the surface of the bar.

\section{Spratt limestone}

In Figure 4.12 it is apparent that fractures initiate at ruptured aggregate grains and widen as they extend through the paste towards the surface of the bar. The nature of grain rupture is demonstrated in Figure 4.16 where grains have become crazed. That paste fracturing initiates at the grain is also clearly demonstrated in that same figure.

\section{Sioux quartzite}

Given the nature of the more rapidly dissolving silica cement in the Sioux quartzite, it is difficult to ascertain whether aggregate grains actually ruptured. The sinuous bright "fractures" passing through grains shown in Figure 4.13 may be where silica cement was dissolved away as opposed to an actual fracture. Compounding the issue is the added consideration of the aggregate itself being a concrete-like material with "aggregate" silica clasts in a matrix of silica cement. Given the nature of paste densification, it is difficult to 
distinguish aggregate grains from cement paste even under cross polarized light illumination.

The higher magnification images in Figure 4.17 show what might best be described as a hybrid failure mode in which fracturing occurs both as a result of aggregate grains rupturing and paste densification. Fractures are not as plastic in appearance as observed in the SRA mortar but separation along aggregate-paste interfaces is apparent. Fractures do not as clearly originate at ruptured aggregate grains as found with Spratt limestone. 

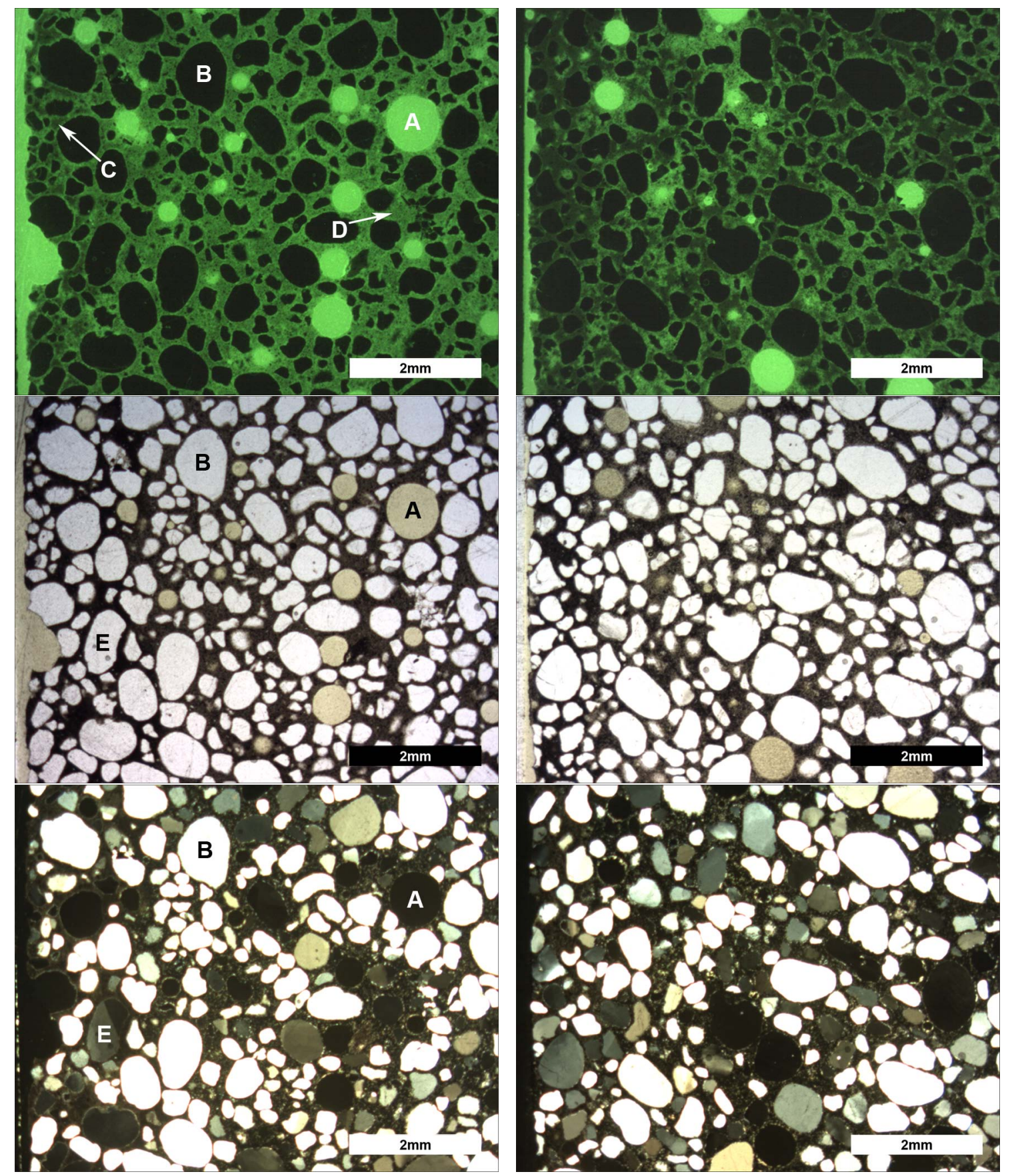

Figure 4.10: Images of thin sections of ASTM C1260 Ottawa sand mortar bars. Bar edge towards left. Images in the left column are of a bar soaked in $1 \mathrm{~N} \mathrm{NaOH}$, those on right of a bar soaked in $1 \mathrm{~N} \mathrm{NaOH}$ in $3.2 \mathrm{M} \mathrm{KAc}$. From top to bottom, epiflourescent, plane polarized light, cross polarized light. 

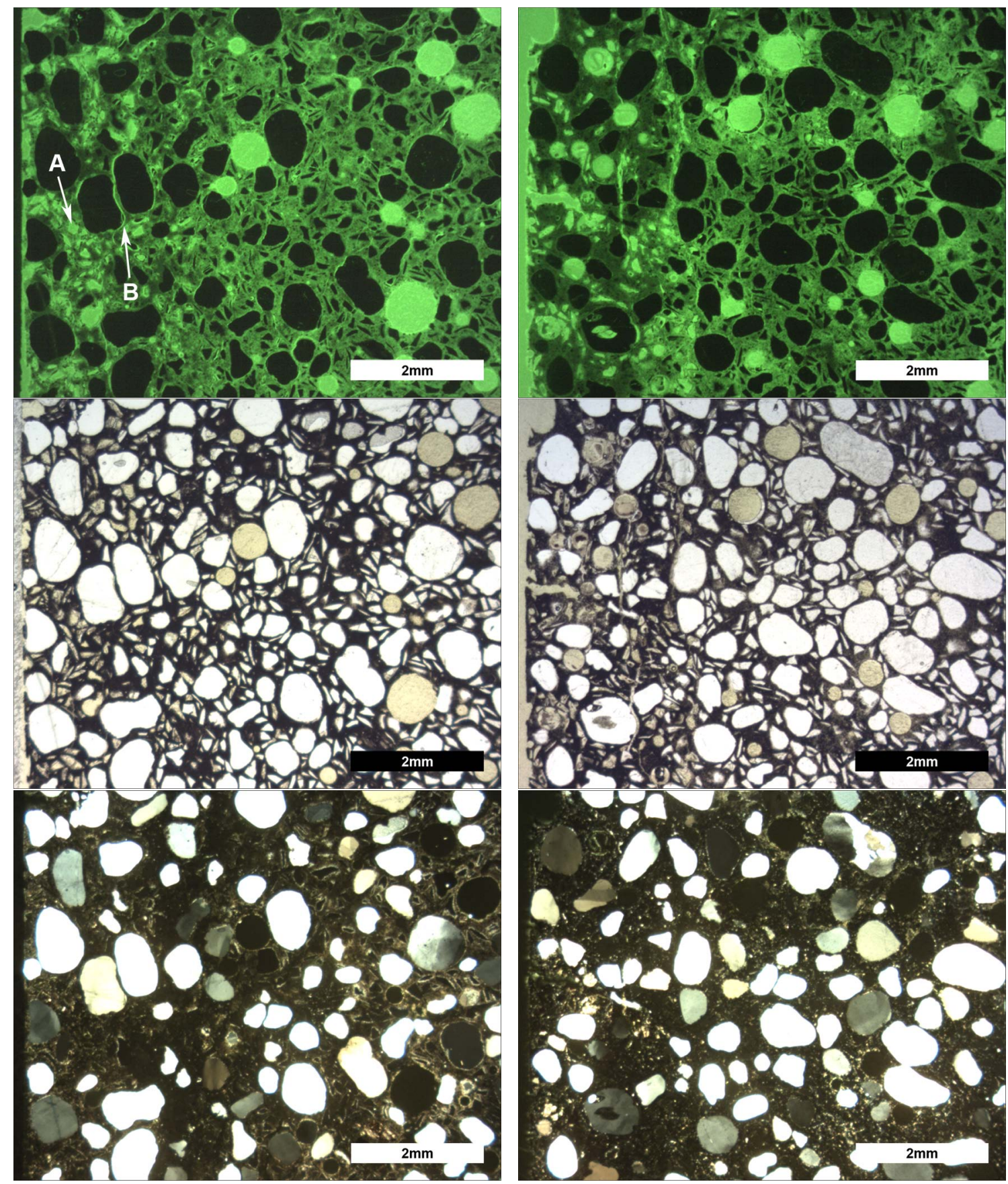

Figure 4.11: Images of thin sections of ASTM C1260 SRA mortar bars. Bar edge towards left. Images in the left column are of a bar soaked in $1 \mathrm{~N} \mathrm{NaOH}$, those on right of a bar soaked in $1 \mathrm{~N}$ $\mathrm{NaOH}$ in $3.2 \mathrm{M} \mathrm{KAc}$. From top to bottom, epiflourescent, plane polarized light, cross polarized light. 

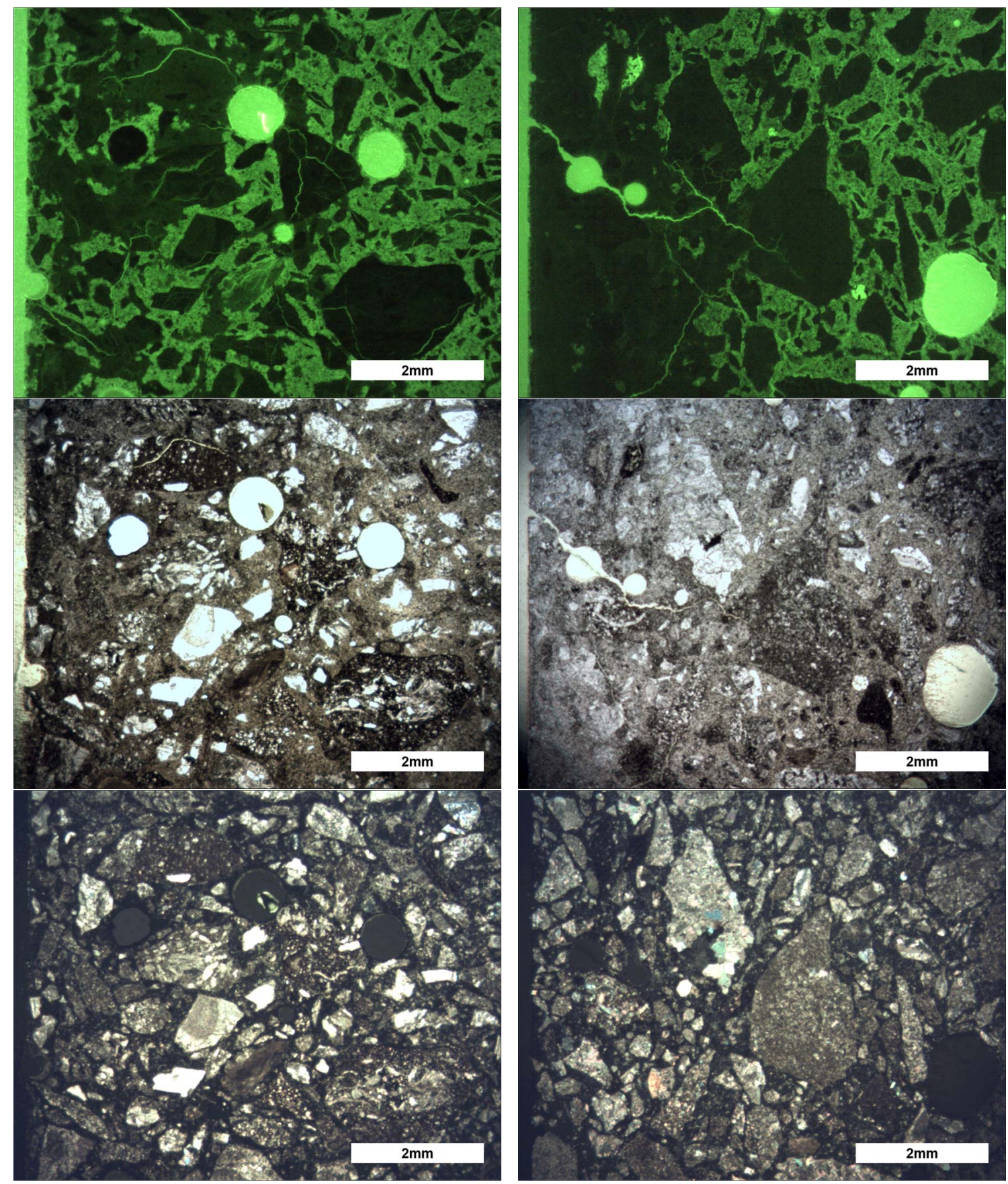

Figure 4.12: Images of thin sections of ASTM C1260 Spratt limestone mortar bars. Bar edge towards left. Images in the left column are of a bar soaked in $1 \mathrm{~N} \mathrm{NaOH}$, those on right of a bar soaked in $1 \mathrm{~N} \mathrm{NaOH}$ in $3.2 \mathrm{M} \mathrm{KAc}$. From top to bottom, epiflourescent, plane polarized light, cross polarized light. 

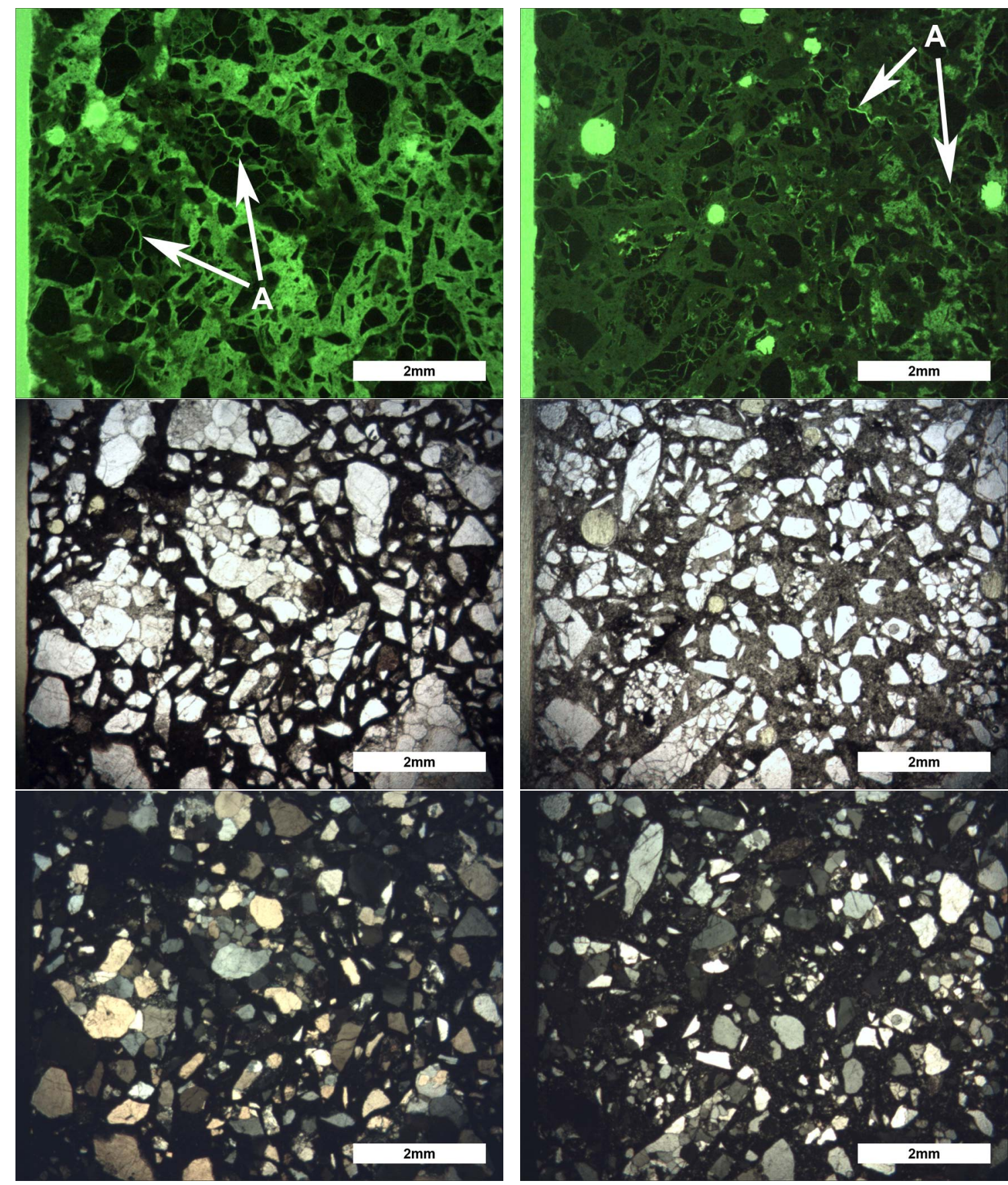

Figure 4.13: Images of thin sections of ASTM C1260 Sioux quartzite mortar bars. Bar edge towards left. Images in the left column are of a bar soaked in $1 \mathrm{~N} \mathrm{NaOH}$, those on right of a bar soaked in $1 \mathrm{~N} \mathrm{NaOH}$ in $3.2 \mathrm{M} \mathrm{KAc}$. From top to bottom, epiflourescent, plane polarized light, cross polarized light. 

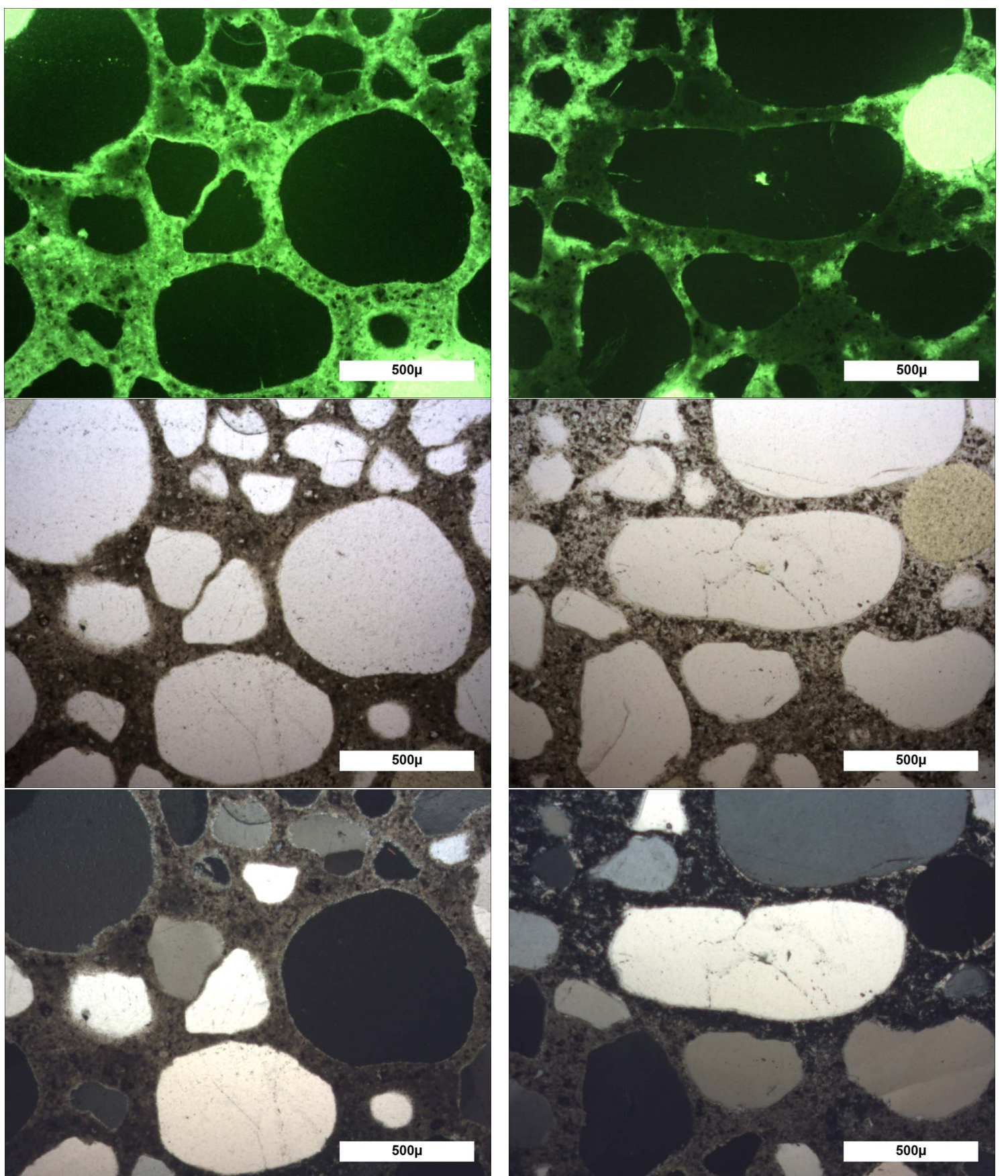

Figure 4.14: Micrographs of Ottawa sand grains in thin section from ASTM C1260 mortar bars. Images in the left column are of a bar soaked in $1 \mathrm{~N} \mathrm{NaOH}$, those on right of a bar soaked in $1 \mathrm{~N} \mathrm{NaOH}$ in $3.2 \mathrm{M} \mathrm{KAc}$. From top to bottom, epiflourescent, plane polarized light, cross polarized light. 

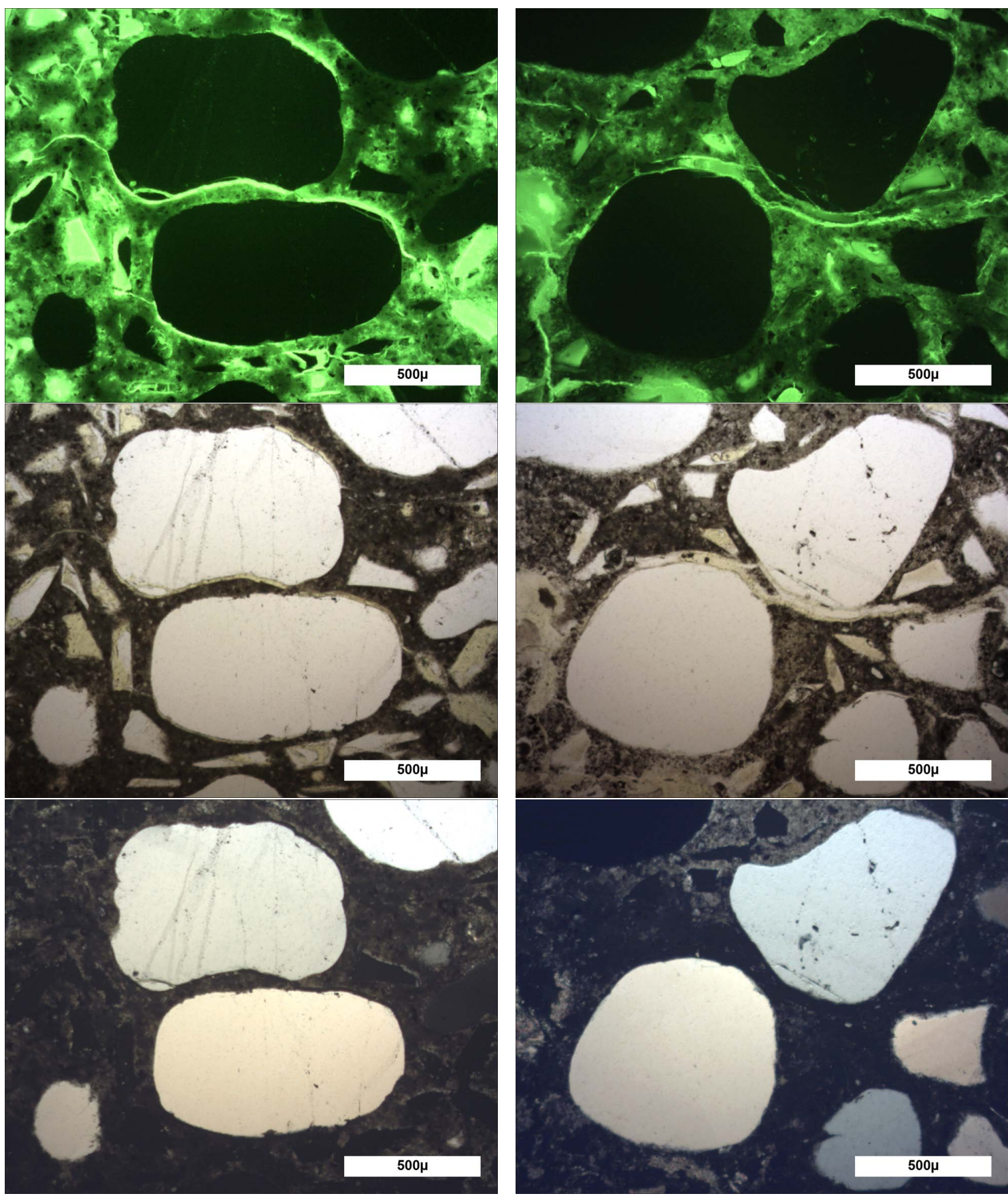

Figure 4.15: Micrographs of SRA grains in thin section from ASTM C1260 mortar bars. Images in the left column are of a bar soaked in $1 \mathrm{~N} \mathrm{NaOH}$, those on right of a bar soaked in $1 \mathrm{~N}$ $\mathrm{NaOH}$ in $3.2 \mathrm{M}$ KAc. From top to bottom, epiflourescent, plane polarized light, cross polarized light. 

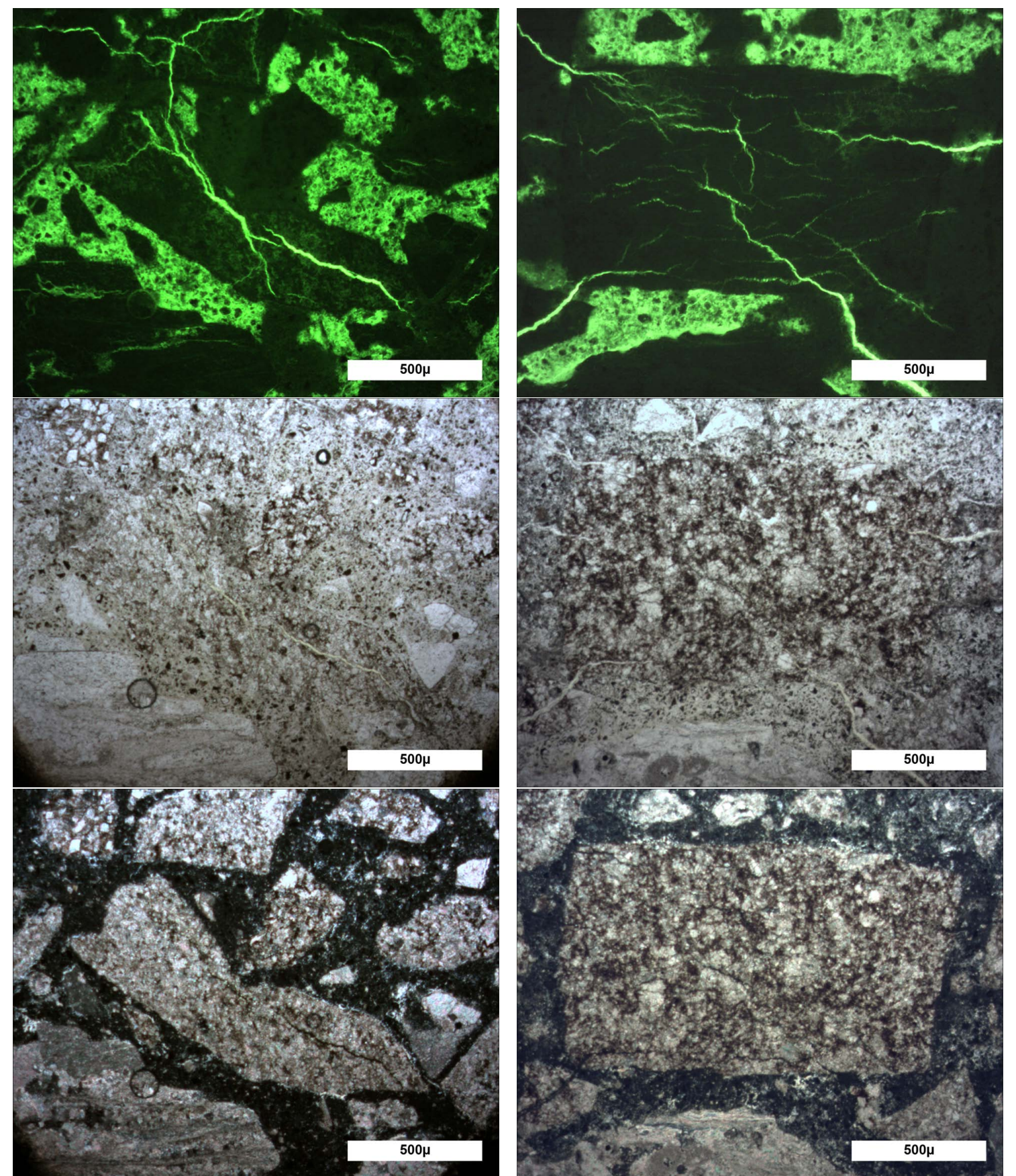

Figure 4.16: Micrographs of Spratt limestone grains in thin section from ASTM C1260 mortar bars. Images in the left column are of a bar soaked in $1 \mathrm{~N} \mathrm{NaOH}$, those on right of a bar soaked in $1 \mathrm{~N} \mathrm{NaOH}$ in $3.2 \mathrm{M}$ KAc. From top to bottom, epiflourescent, plane polarized light, cross polarized light. 


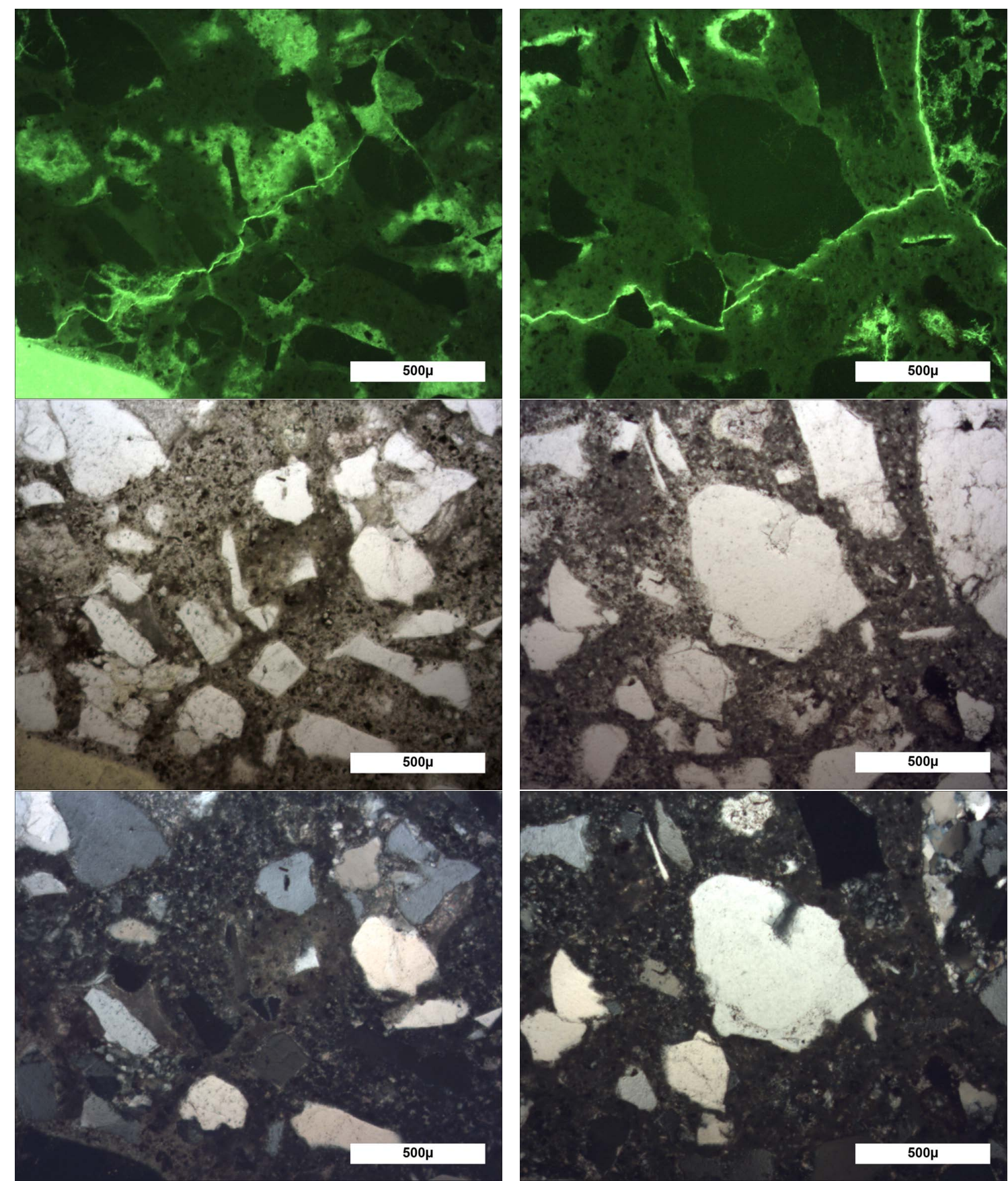

Figure 4.17: Micrographs of Sioux quartzite grains in thin section from ASTM C1260 mortar bars. Images in the left column are of a bar soaked in $1 \mathrm{~N} \mathrm{NaOH}$, those on right of a bar soaked in $1 \mathrm{~N} \mathrm{NaOH}$ in $3.2 \mathrm{M} \mathrm{KAc}$. From top to bottom, epiflourescent, plane polarized light, cross polarized light. 


\section{Discussion}

Excluding Ottawa sand and SRA mortars, the addition of potassium acetate to the 1N $\mathrm{NaOH}$ solution prescribed by ASTM C1260 did indeed exacerbate expansion as shown by the expansion rate curves for Sioux quartzite, local basalt and Spratt limestone in Figure 4.2.

Whereas researchers have reported that innocuous aggregates, like Ottawa sand, have produced deleterious expansion when soaked in KAc-containing solutions, no measurable expansion was produced in any of the solutions investigated in this research (Figure 4.1). Expansion reported by others was measured only after extending the duration of the soak period. It seems reasonable that under the conditions employed by AMBT methods, measurable expansion would be produced with any aggregate given a sufficiently long period to react.

Expansion of the SRA mortar was greatest in the $1 \mathrm{~N} \mathrm{NaOH}$ solution, setting it apart from the other reactive aggregates. This suggests that there is a different expansion process at work with this system. This was confirmed upon petrographic evaluation of mortars, which demonstrated that the failure mechanism in the SRA mortars was much different from that observed in the other mortars.

Mitigation of expansion was demonstrated when portland cement was replaced by a suitable SCM, as shown in Figures 4.4 through 4.9. The degree of mitigation is related to the replacement rate with higher replacement rates mitigating expansion to a greater degree. This remains true regardless of soak solution chemistry.

A relationship between fly ash composition and mitigation potential was established and is demonstrated in Figures 4.4 through 4.8. The relationship holds for all of the solution chemistries investigated. As shown in Figures 4.5 and 4.7, low calcium fly ash at a 30\% replacement rate produced the lowest expansion rate with both Spratt limestone and Sioux quartzite in all of the soak solutions. 
Ground granulated blast furnace slag is typically high in calcium as it is the product of fluxing cast iron melts with limestone (calcium carbonate). As demonstrated by the expansion rate curves in Figures 4.8 and 4.9, at 40\% replacement, it has a mitigation potential roughly equivalent to mid-to high calcium content fly ash at a $30 \%$ replacement rate.

There is also a relationship between the expansion rate and species of alkali metal hydroxide used to make the soak solution. This is apparent when comparing expansion rate curves for like-mortars soaked in $1 \mathrm{~N} \mathrm{NaOH}$ in $3.2 \mathrm{M} \mathrm{KAc}$ and $1 \mathrm{~N} \mathrm{KOH}$ in $3.2 \mathrm{M}$ $\mathrm{KAc}$. In all cases, the $\mathrm{KOH}-$ containing solution produced lower expansion rates.

Petrographic examination of mortars revealed that expansion occurred due to two distinct failure mechanisms: 1) Rupturing of aggregate grains as observed in Spratt limestone mortars. 2) Expansion of cement paste as exhibited by the SRA mortars. The failure mechanism for a given aggregate did not change with the addition of KAc to the soak solution, i.e. Spratt limestone mortars expanded as a result of rupturing of aggregate grains when soaked in either $1 \mathrm{~N} \mathrm{NaOH}$ or $1 \mathrm{~N} \mathrm{NaOH}$ in $3.2 \mathrm{M} \mathrm{KAc}$.

The conclusion that the SRA mortars fractured due to paste expansion is based upon the nature of the fractures found in those mortars. No ruptured aggregate grains were found; instead fractures occurred near paste-aggregate grain interfaces sub-parallel to the exposed surface of the bar. The glass proved to be soluble in the soak solutions and grains nearest the surface of the bar were completely dissolved. Dissolution products had to diffuse into the cement pore system, which would have a fixed capacity to accommodate those products. As the pore system became saturated with reaction products, pressure would build near the reaction site, causing stress in the adjacent cement matrix. Larger Ottawa sand grains nearer the interior of the bar would act as stress risers as they are restrained from moving. Force lines would therefore deform around those barrier grains, placing the paste-grain interface nearest the edge of the bar under tension. The cement paste fails under tensile loading at that interface, forming the curved fractures that follow the contour of the restraining aggregate grain seen in Figure 4.15 . 
Fractures play a dual role in the ASR process. Not only are they a root cause of expansion, once formed, they act as channels, increasing the ingress rate of soak solution into the interior of the bar. This will play a more significant role with the Spratt limestone as fractures are frequently normal to the surface of the bar as opposed to sub-parallel as is the case in the SRA mortars. Fracturing bypasses the much slower diffusion of soak solution through the cement pore system, essentially creating brand new fully exposed surfaces for the soak solution to penetrate and allowing expansion to continue.

Paste densification was apparent in all of the mortars, suggesting that dissolution product diffuses into the paste pore system as ASR progresses. The nature of densification is much different upon comparing different mortars. Spratt limestone and Sioux quartzite both produced significant densification near the exposed surface, but deeper in the bar Spratt limestone produced densification of a more spotty nature. While the degree of paste densification in Sioux quartzite mortars was much greater than that observed in Ottawa sand mortars, they have similar features. Both produce a more uniform densification and deeper into the Sioux quartzite bars a gradient with proximity to aggregate grains similar to that observed in the Ottawa sand mortars is apparent. Paste densification in SRA mortars was similar to that of Ottawa sand and Sioux quartzite mortars.

Comparing expansion results between mortars soaked in $1 \mathrm{~N} \mathrm{NaOH}$ and $1 \mathrm{~N} \mathrm{NaOH}$ in 3.2M KAc yields more similarities than differences. In Figure 4.3, excluding the SRA mortar, the ranking of aggregate by expansion is the same in all of the solutions. Each of the individual aggregates reacted similarly in the ASTM C1567 tests; high calcium fly ash was least effective and low calcium fly ash most effective at mitigating expansion. Petrographic evaluation of the mortars also found more similarities than differences. Densification of paste occurred regardless of soak solution chemistry but was generally more severe in mortars soaked in KAc-containing solutions. Evidence therefore supports that the exacerbation of ASR-expansion found in laboratory testing is not the result of a new process, but rather acceleration of the phenomena responsible for classic ASRinduced expansion. 


\section{Future Work}

While the imperative imposed on industry by more stringent aggregate testing has been removed as a result of the FAA's revocation of the modified aggregate testing procedure, there is need to better understand the ASR-induced expansion mechanism that is at the center of this research effort.

Virtually all research of ASR expansion mechanisms has been constrained by the 1955 Powers and Steinour model thereby granting imprimatur to that model. Results from this and related research have highlighted both the shortcomings of that model and the lack of understanding of the fundamental and complex chemical and physical processes responsible for expansion.

A critical review of the widely accepted ASR model is overdue. Renewed research focusing on silica chemistry and transport phenomena as it relates to ASR distress is a key step towards developing more effective mitigation strategies and aggregate testing protocols. As aggregate supplies continue to dwindle and use of recycled concrete aggregate increases, testing of aggregate and development of effective mitigation methods will become increasingly more important. 


\section{Conclusions}

Potassium acetate deicing chemicals exacerbate ASR-induced expansion of reactive aggregates within the context of the AMBT. Mitigation of expansion in KAc-containing solutions is possible with judicious replacement of portland cement with suitable SCMs. Low calcium fly ash has a greater potential for mitigating expansion than does high calcium fly ash. Ground granulated blast furnace slag was also found to be effective, but was less effective than low calcium fly ash.

Potassium hydroxide produced lower expansion rates than did sodium hydroxide with KAc-containing soak solutions.

Petrographic examination of mortars after AMBT revealed two distinct expansion processes. One involves the more typical rupturing of aggregate grains, the other results from expansion of the cement paste itself. Densification of paste was apparent in all mortars and was found to be greater in mortars soaked in KAc-containing solution.

The expansion process in the presence of KAc deicing chemicals, and in the context of the AMBT, is accelerated but does not appear to be different from the process at work in tests conducted with $1 \mathrm{~N} \mathrm{NaOH}$. 


\section{References}

1. United States. Environmental Protection Agency. Office of Water. Preliminary data summary airport deicing operations (revised). (U.S. Environmental Protection Agency, Office of Water: Washington, DC, 2000).

2. Fisher, D. J. et al. THE ACUTE WHOLE EFFLUENT TOXICITY OF STORM WATER FROM AN INTERNATIONAL AIRPORT. Environmental Toxicology and Chemistry 1103-1111 (1995).

3. Corsi, S. R., Geis, S. W., Bowman, G., Failey, G. G. \& Rutter, T. D. Aquatic Toxicity of Airfield-Pavement Deicer Materials and Implications for Airport Runoff. Environmental Science \& Technology 43, 40-46 (2009).

4. Rangaraju, P. R., Sompura, K. R., Olek, J., Diamond, S. \& Lovell, J. Potential for Development of Alkali-Silica Reaction in Presence of Airfield Deicing Chemicals. Proceedings of the 8th International Conference on Concrete Pavements 1269-1289 (2005).

5. Thomas, M. D. A. Deterioration of Concrete Exposed to Potassium Acetate. (2011).

6. FAA EB\#70. (2005).

7. Rangaraju, P. Distress Mechanisms in Concrete Pavements Subjected to KAc Deicer. (2011).

8. Cline, G. Recent Updates and Changes. Presented at PCA Concrete Durability Session (2011).

9. Taylor, H. F. W. Cement chemistry. (T. Telford: London, 1997). 
10. Idorn, G. M. Concrete progress : from antiquity to third millenium. (Thomas Telford: London, 1997).

11. ASTM International ASTM C856 - 11 Standard Practice for Petrographic Examination of Hardened Concrete. at $<$ http://www.astm.org/Standards/C856.htm $>$

12. Helmuth, R. A., Strategic Highway Research Program (U.S.) \& Construction Technology Laboratories (Portland Cement Association) Alkali-silica reactivity : an overview of research. (Strategic Highway Research Program, National Research Council: Washington, DC, 1993).

13. ASTM International ASTM C1260-07 Standard Test Method for Potential Alkali Reactivity of Aggregates (Mortar-Bar Method). at $<$ http://enterprise.astm.org/filtrexx40.cgi?+REDLINE_PAGES/C1260.htm>

14. ASTM International ASTM C289-07 Standard Test Method for Potential AlkaliSilica Reactivity of Aggregates (Chemical Method). at $<\mathrm{http}: / /$ enterprise.astm.org/filtrexx40.cgi?/usr6/htdocs/newpilot.com/SUBSCRIPTIO N/REDLINE_PAGES/C289.htm>

15. ASTM International ASTM C1293-08b Standard Test Method for Determination of Length Change of Concrete Due to Alkali-Silica Reaction. at $<$ http://enterprise.astm.org/filtrexx40.cgi?/usr6/htdocs/newpilot.com/SUBSCRIPTIO N/REDLINE_PAGES/C1293.htm>

16. ASTM International ASTM C1567-11 Standard Test Method for Determining the Potential Alkali-Silica Reactivity of Combinations of Cementitious Materials and Aggregate (Accelerated Mortar-Bar Method). at 
$<$ http://enterprise.astm.org/filtrexx40.cgi?/usr6/htdocs/newpilot.com/SUBSCRIPTIO N/REDLINE_PAGES/C1567.htm>

17. Adams, N. \& Stokes, D. B. Using advanced lithium technology to combat ASR in concrete. Concrete international 24, 99-102 (2002).

18. Folliard, K. J. et al. Guidelines for the use of lithium to mitigate or prevent alkalisilica reaction (ASR). (U.S. Dept. of Transportation, Federal Highway Administration, Research, Development, and Technology, Turner-Fairbank Highway Research Center; Available to the public through the National Technical Information Service: McLean, VA; Springfield, VA, 2003).

19. Van Dam, T., Sutter, L., Smith, K., Wade, M. \& Peterson, K. Guidelines for Detection, Analysis, and Treatment of Materials-Related Distress in Concrete Pavements, Volume 1: Final Report. (FHWA-RD-01: 2002).

20. Van Dam, T., Sutter, L., Smith, K., Wade, M. \& Peterson, K. Guidelines For Detection, Analysis, And Treatment Of Materials-Related Distress In Concrete Pavements-Volume 2: Guidelines Description and Use. (2002).

21. Sutter, L., Peterson, K., Van Dam, T., Smith, K. \& Wade, M. GUIDELINES FOR DETECTION, ANALYSIS, AND TREATMENT OF MATERIALS-RELATED DISTRESS IN CONCRETE PAVEMENTS-VOLUME 3: CASE STUDIES USING THE GUIDELINES. (2002).

22. Fournier, B., Berube, M. A., Folliard, K. J. \& Thomas, M. Report on the Diagnosis, Prognosis, and Mitigation of Alkali-Silica Reaction (ASR) in Transportation Structures. (2010). 
23. Prezzi, M., Monteiro, P. J. M. \& Sposito, G. Alkali-Silica Reaction, Part I: Use of the Double-Layer Theory to Explain the Behavior of Reaction-Product Gels. ACI materials journal 94, (1997).

24. Rodrigues, F. A., Monteiro, P. J. M. \& Sposito, G. The alkali-silica reaction: The surface charge density of silica and its effect on expansive pressure. Cement and Concrete Research 29, 527-530 (1999).

25. Rodrigues, F. A., Monteiro, P. J. M. \& Sposito, G. The alkali-silica reaction: The effect of monovalent and bivalent cations on the surface charge of opal. Cement and Concrete Research 31, 1549-1552 (2001).

26. Iler, R. K. The chemistry of silica : solubility, polymerization, colloid and surface properties, and biochemistry. (Wiley: New York, 1979).

27. Ichikawa, T. \& Miura, M. Modified model of alkali-silica reaction. Cement and concrete research. 37, 1291 (2007).

28. Ichikawa, T. Alkali-silica reaction, pessimum effects and pozzolanic effect. Cement and Concrete Research 39, 716-726 (2009).

29. Taguchi, M., Chatterji, S. \& Kawamura, M. On the specific effect of ions on the rate of alkali-silica reaction. Cement and Concrete Research 22, 609-611 (1992).

30. Hou, X., Struble, L. J. \& Kirkpatrick, R. J. Formation of ASR gel and the roles of CS-H and portlandite. Cement and Concrete Research 34, 1683-1696 (2004).

31. Katayama, T., Tagami, M., Sarai, Y., Izumi, S. \& Hira, T. Alkali-aggregate reaction under the influence of deicing salts in the Hokuriku district, Japan. Materials Characterization 53, 105-122 (2004). 
32. Kawamura, M. \& Takeuchi, K. Alkali-silica reaction and pore solution composition in mortars in sea water. Cement and Concrete Research 26, 1809-1819 (1996).

33. Kawamura, M. \& Ichise, M. Characteristics of alkali-silica reaction in the presence of sodium and calcium chloride. Cement and Concrete Research 20, 757-766 (1990).

34. Shi, X. et al. Deicer impacts on pavement materials: Introduction and recent developments. Open Civil Engineering Journal 3, 16-27 (2009).

35. Chatterji, S., Thaulow, N. \& Jensen, A. D. Studies of alkali-silica reaction. Part 4. Effect of different alkali salt solutions on expansion. Cement and Concrete Research 17, 777-783 (1987).

36. Rangaraju, P. \& Olek, J. Potential for Acceleration of ASR in the Presence of PavementDeicing Chemicals. IPFR Project 002-03

37. Stark, J. \& Giebson, C. Influence of Acetate and Formate Based Deicers on ASR in Airfield Concrete Pavements.

38. Rangaraju, P. R. Mitigation of ASR in Presence of Pavement Deicing Chemicals, Report No. (IPRF-01-G-002-04-8, IPRF Program Management Office, Skokie, Illinois: 2007). 